\title{
The role of the Kurdish Press (1898-1920) in the deployment and Emergence of the Kurdish Literary Arts and Literary Criticism
}

\author{
Ali Tahir Barznji ${ }^{1}$
}

Received: March 23, 2016

\author{
Othman Hamad Dashty ${ }^{2}$
}

Reviewed: May 03, 2016

Accepted: May 11, 2016

\begin{abstract}
Literary output is the sum of the process of artistic creativity. Literary study is as science to literature which forms one side of the triangle, along with two other sides of the literary theory and the history of literature. Literary criticism studies and analyzes literary outcomes and evaluates them from intellectual, literary and artistic points of view. Due to the delay in the appearance of books and printing presses and publishing houses in the Kurdish language, the Kurdish press since its inception at the beginning of the twentieth century has played an active role and has undertaken the task of spreading the products of Kurdish literature where poetry formed the greatest part. Also, the Kurdish press has contributed from its early beginning, especially the period between the emergence of the first newspaper in Kurdish in 1898 to the ends of the first World war in 1920 and the emergence of modern literary arts in the Kurdish language, whether prose (Essay, Artistic story, and theatrical texts) or poetic types (Epic, poetic story and prose poem). Moreover, the first attempts to study literary criticism emerged and later evolved into an integrated technical literary work according to the plans and curricula to become an integrated cash scientific criticism theory. This study examines the role of the Kurdish press, between the period (1898-1920) in the deployment and the emergence of Kurdish literary prose and poetry, as well as tracing the footsteps of the emergence and development of the critical process in the Kurdish literature in that time period exclusively.
\end{abstract}

Recommended citation:

Barznji, A. T., \& Dashty, O. H. (2016). The role of the Kurdish Press (1898-1920) in the deployment and Emergence of the Kurdish Literary Arts and Literary Criticism. International Journal of Kurdish Studies 2 (3), $23-37$.

1. Ass. professor, Department of Kurdish language, Faculty of language, University of Sulaimani, Sulaimani, Kurdistan Region - F.R. Iraq. email; d.ali.taher@ hotmail.com

2. Ass. professor, Department of Kurdish language, Faculty of education, Koya University

Daniel Mitterrand Boulevard, Koya KOY45, Kurdistan Region - F.R. Iraq. email;

Osman.hamad@koyauniversity.org 


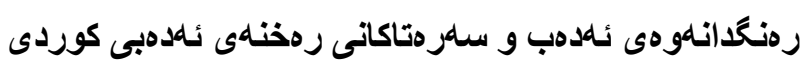

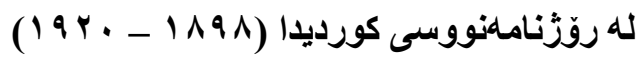

\section{بِيّندكى}

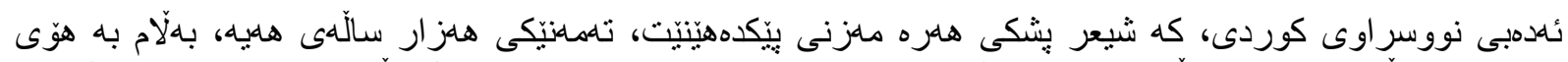

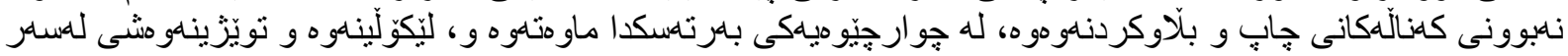

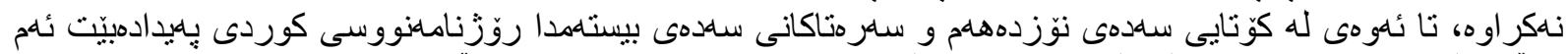

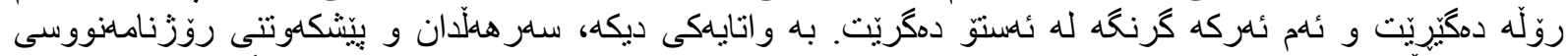

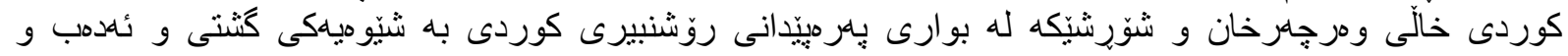

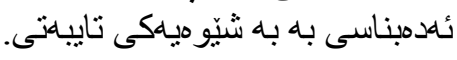

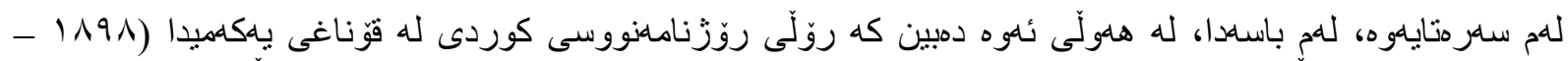

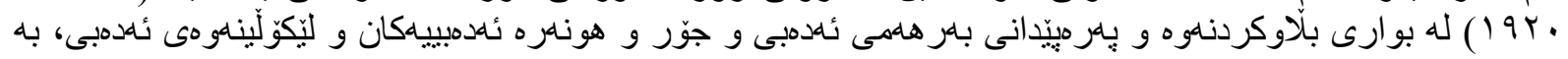

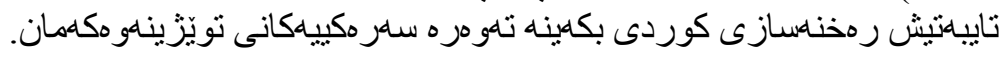

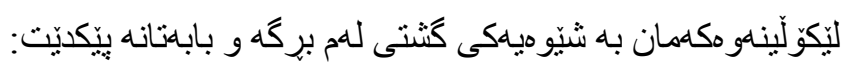

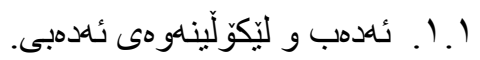

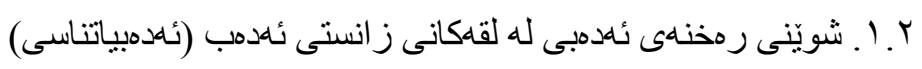

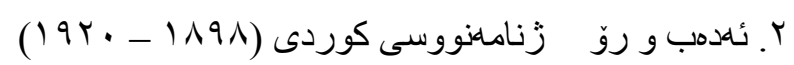

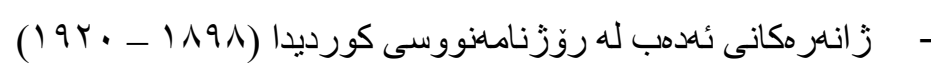

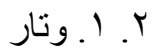

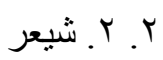

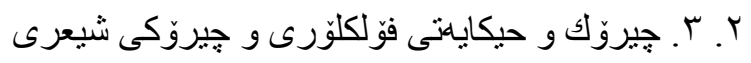

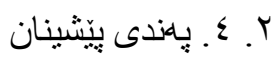

r.

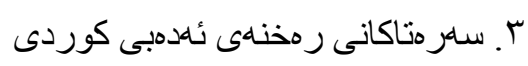

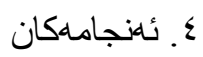

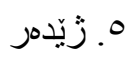




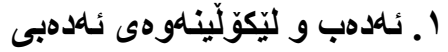

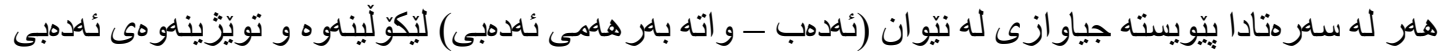

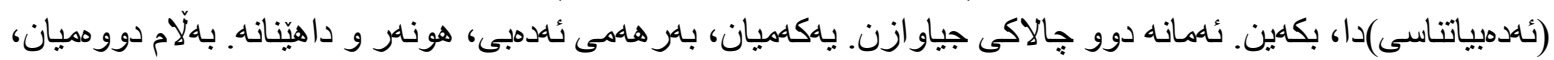

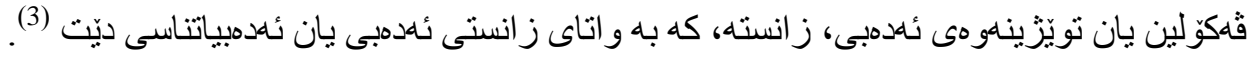

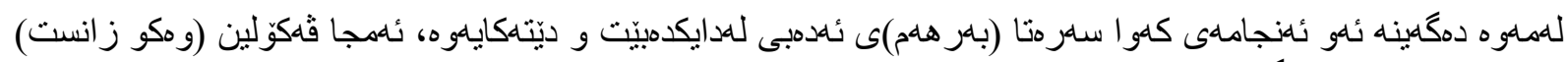

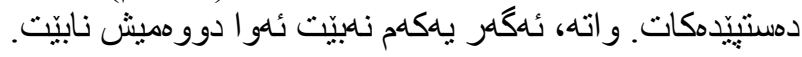

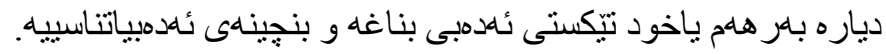

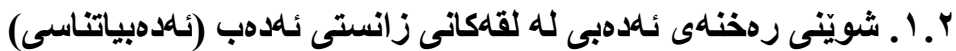

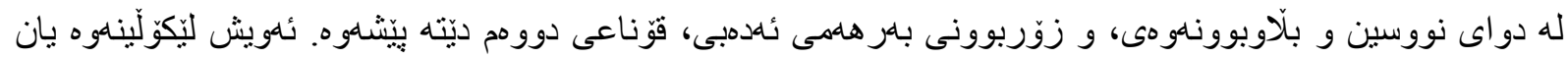

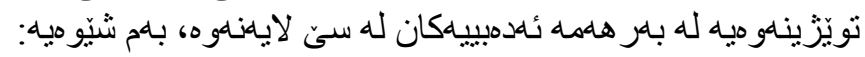

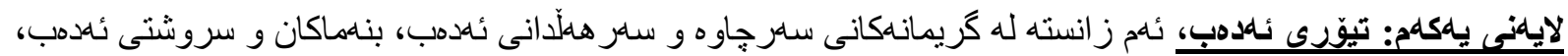

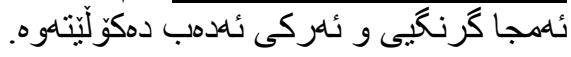

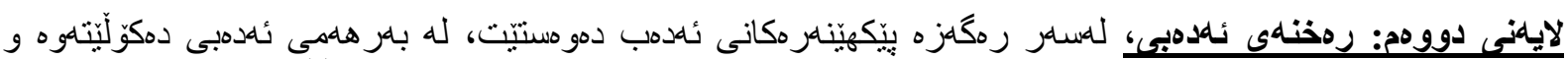

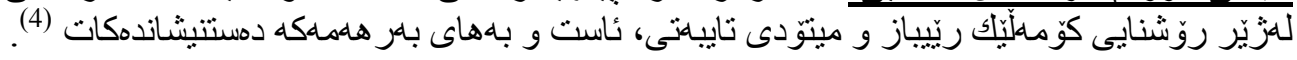

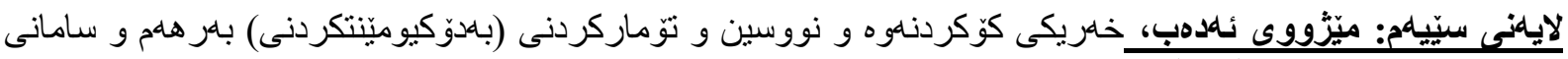

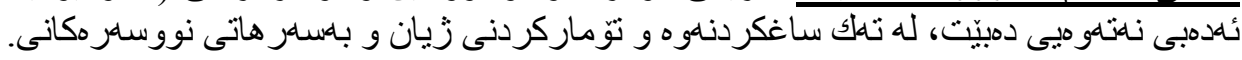
تيوّرى نئهدهب

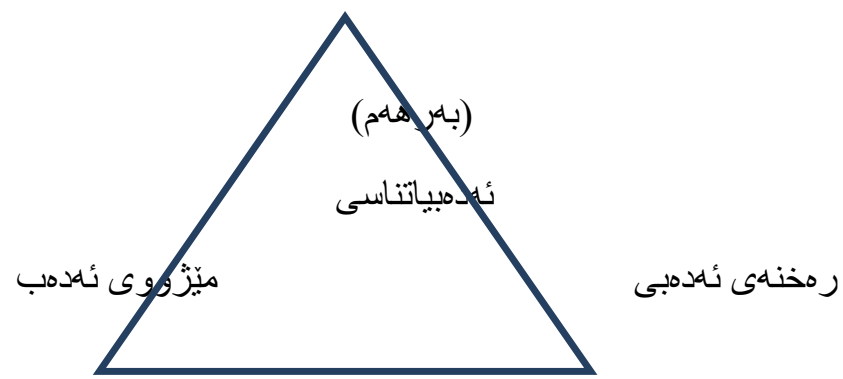

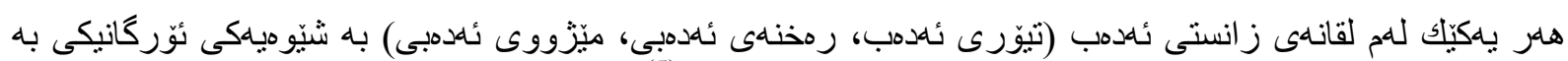

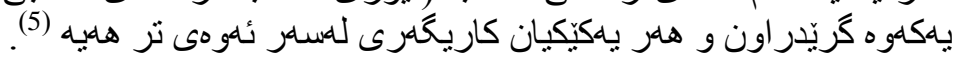

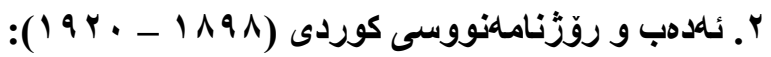

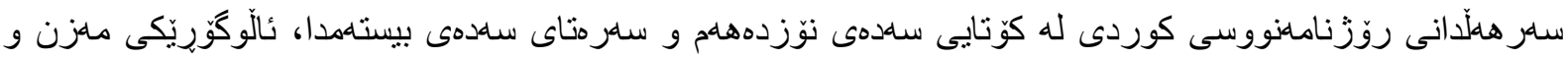

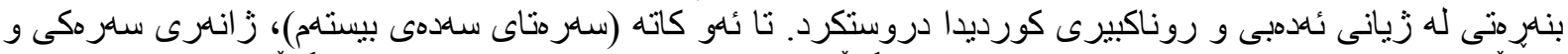

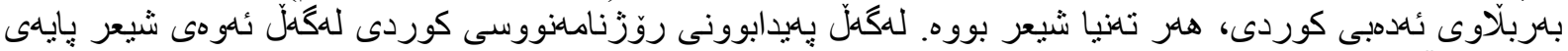

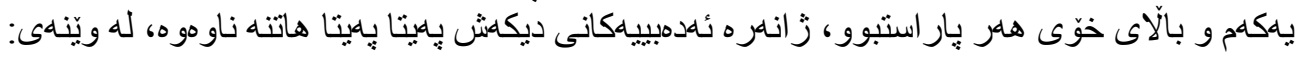

$$
\begin{aligned}
& \text { ك) كاردى، تيوّرى ئلمدب: ـ } 1
\end{aligned}
$$

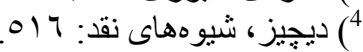

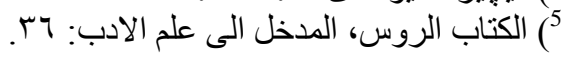




$$
\text { - } \quad \text { - }
$$

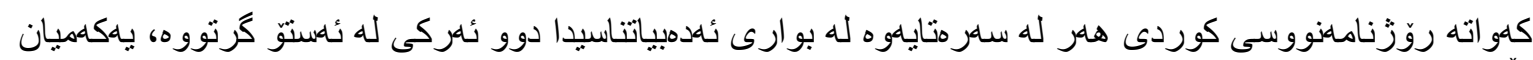

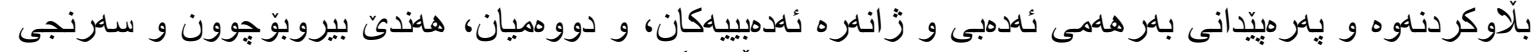

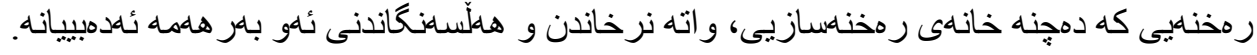

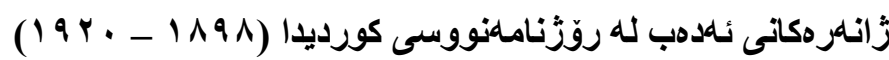

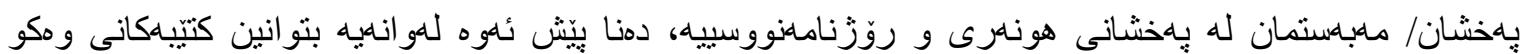

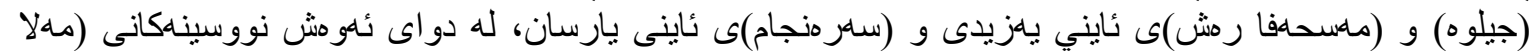

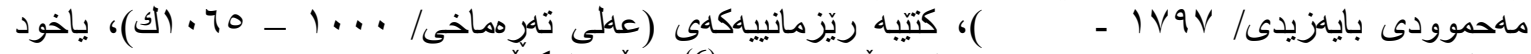

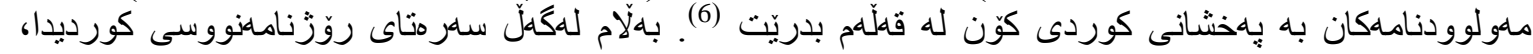

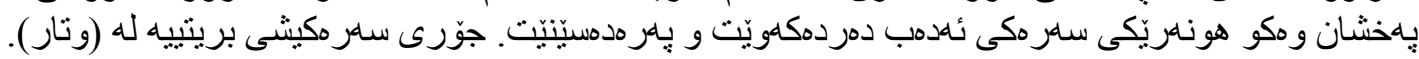

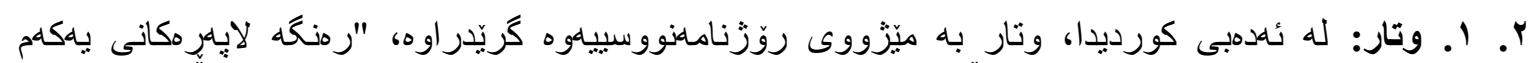

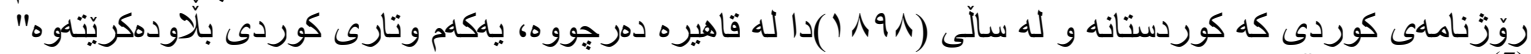

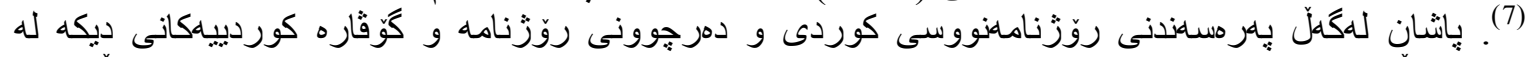

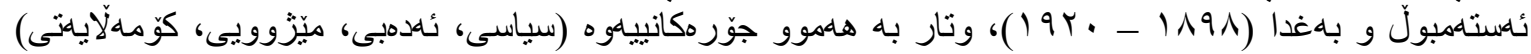

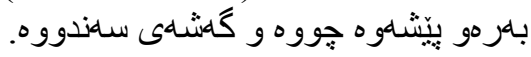

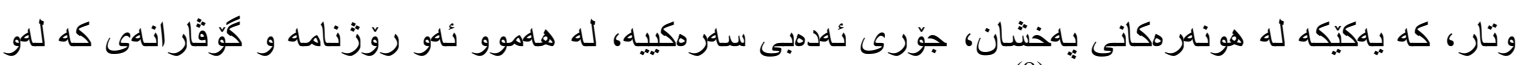

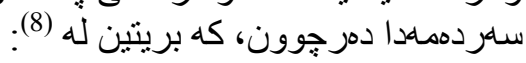

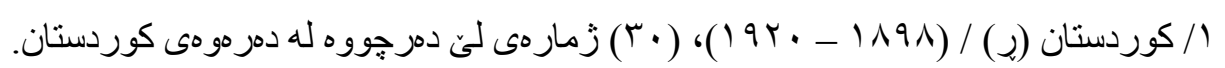

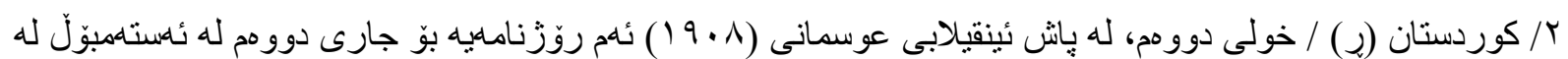

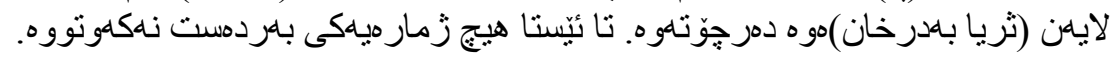

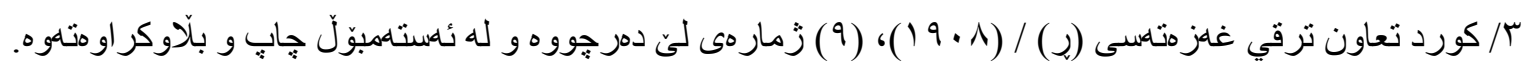

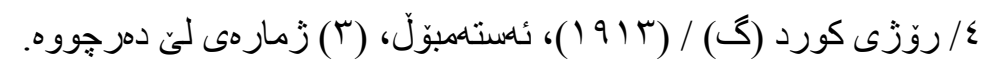

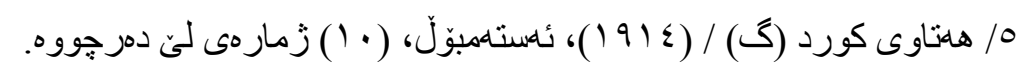

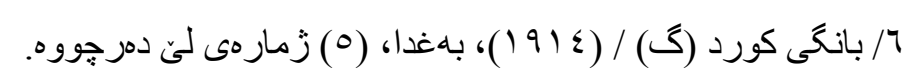

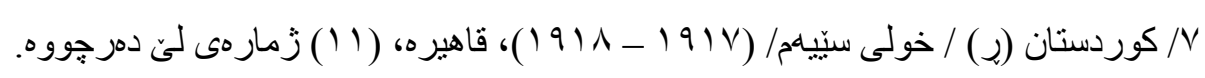

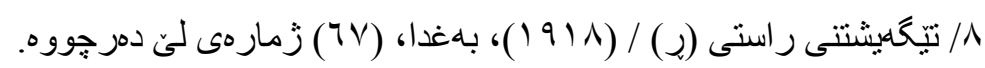

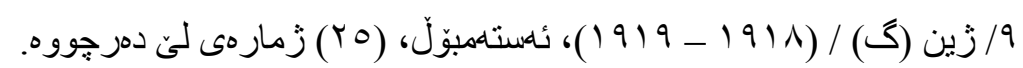

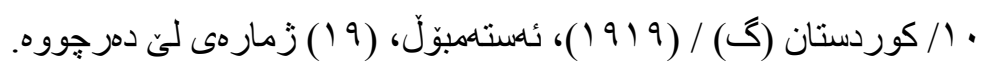

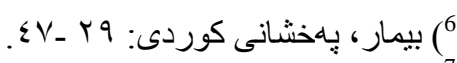

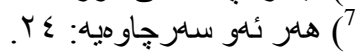

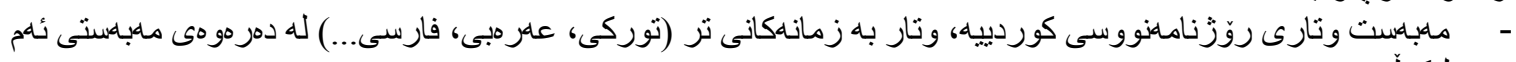

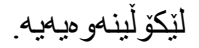

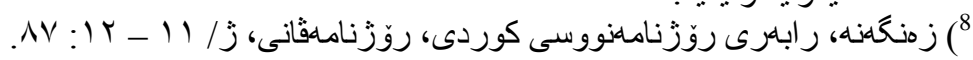




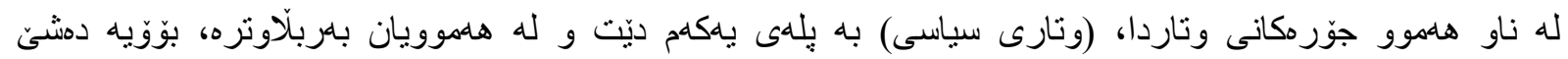

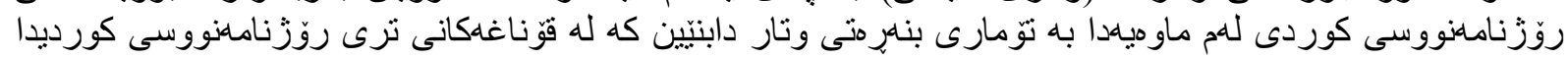

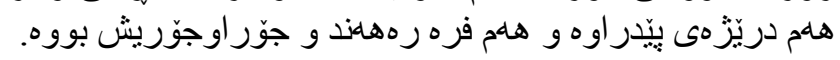

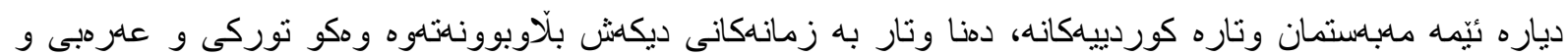

فارسى.

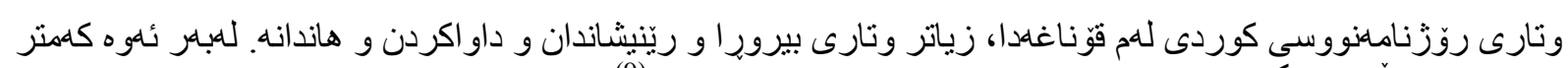

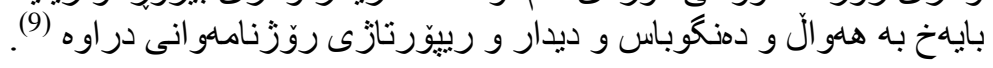

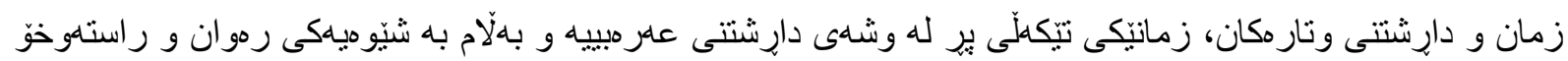

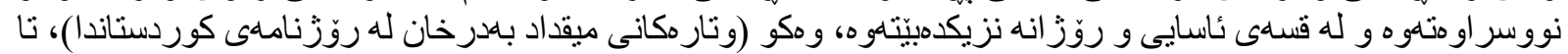

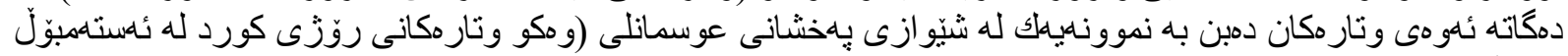

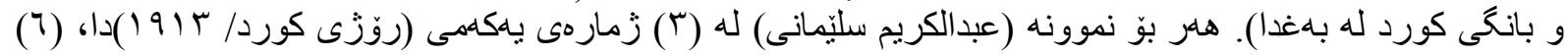

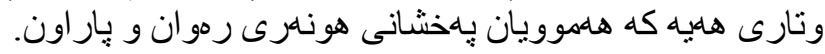

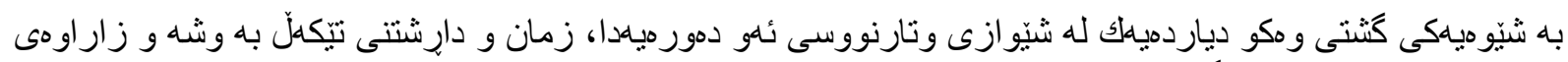

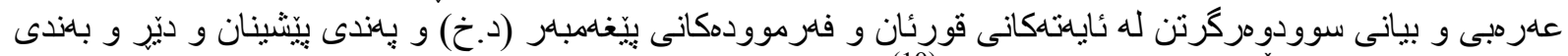

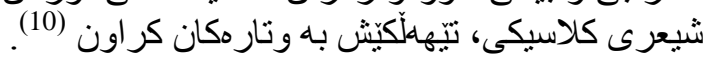

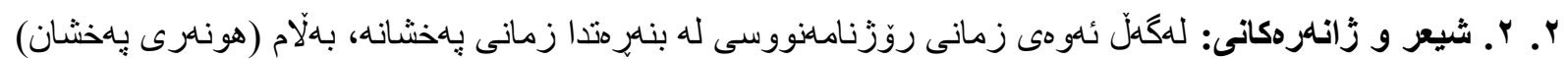

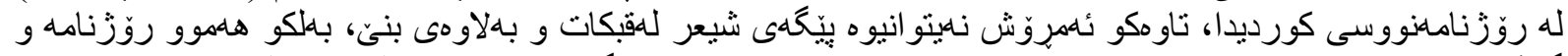

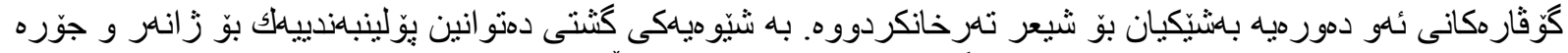

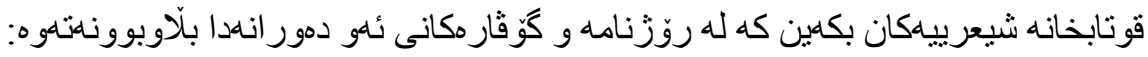

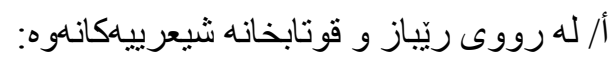

- شيعرى كلاسيك/ له نموونهى شيعرى (ملاى جزيرى، نالى، سالم، كوردى، مهحوى، شيخ رمزا، سيايوّش،

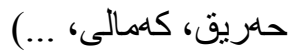

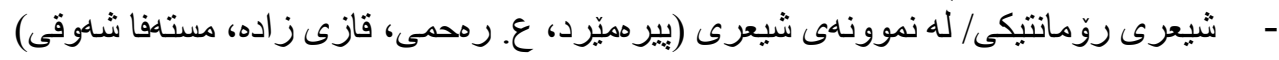

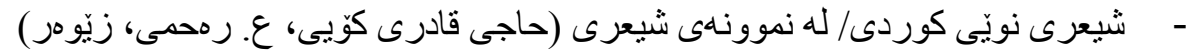

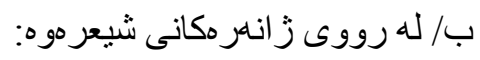

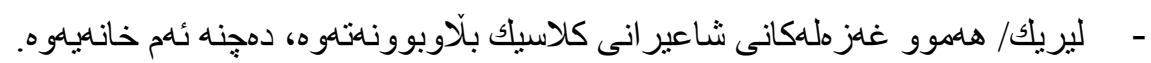

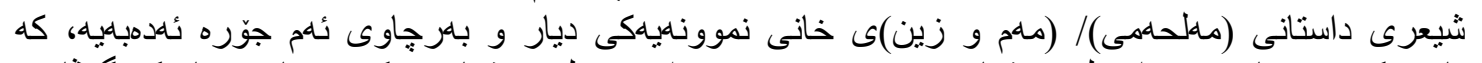

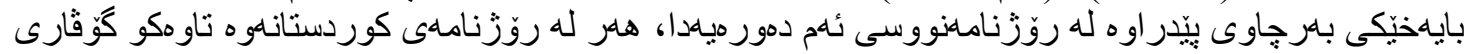

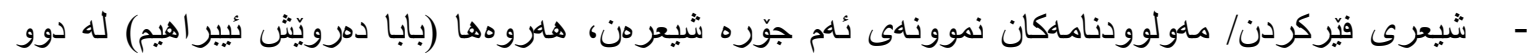

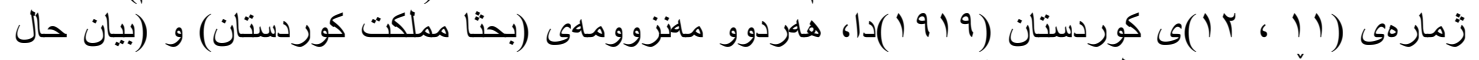

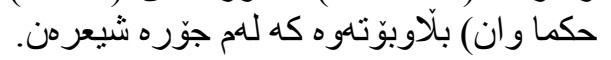

ج/ بابهنهانى ديكهى شيعر /

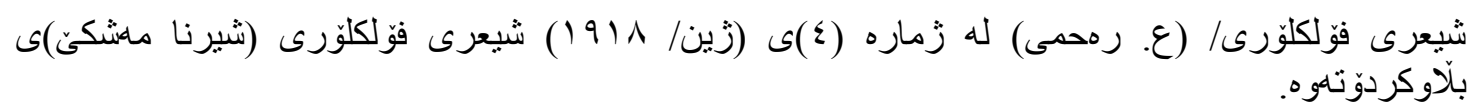

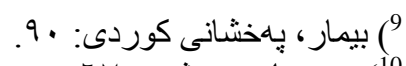

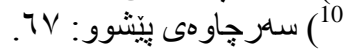




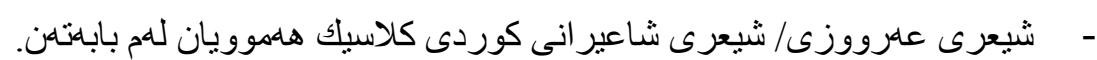

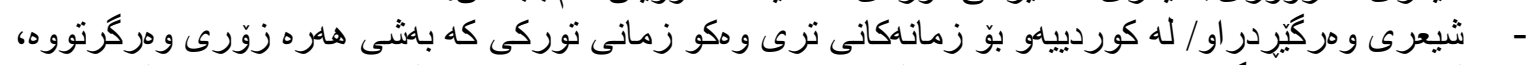

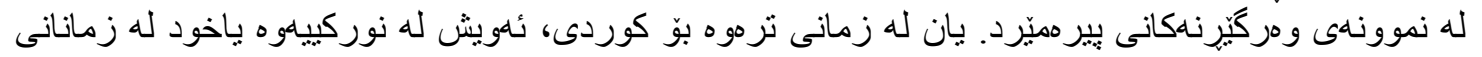

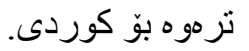

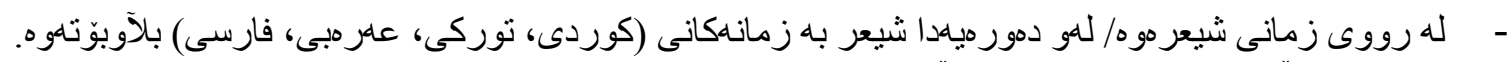

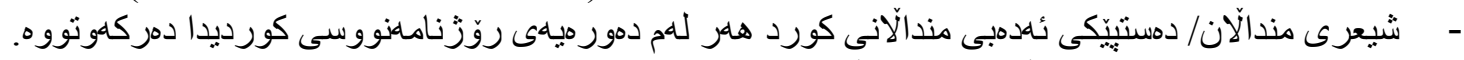

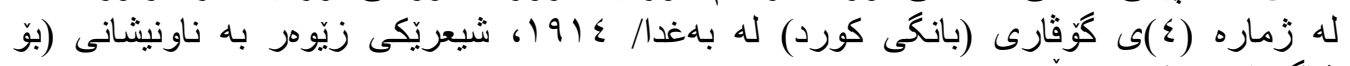

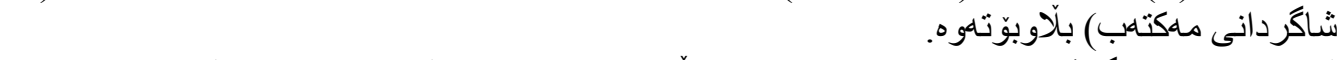

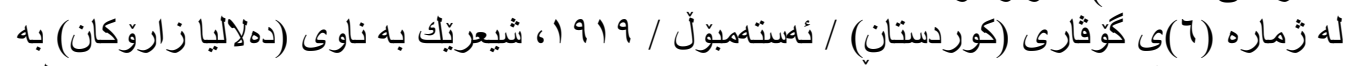

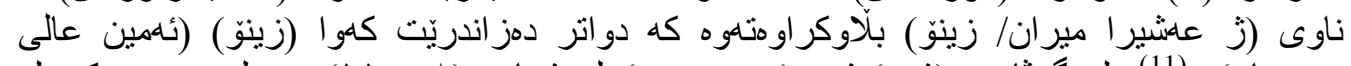

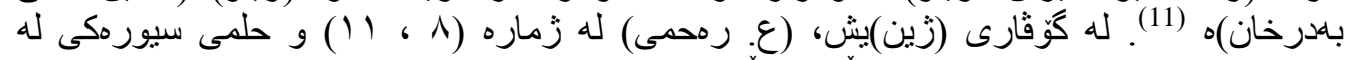

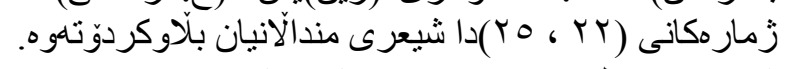

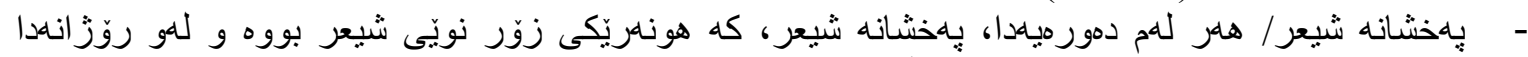

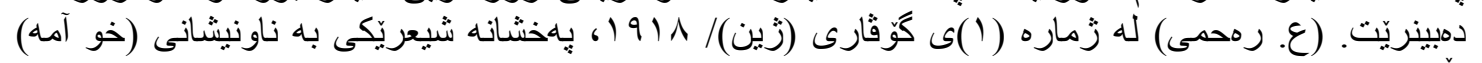

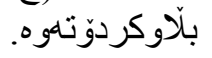

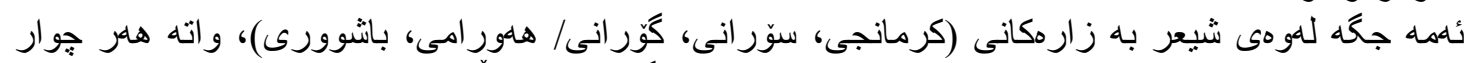

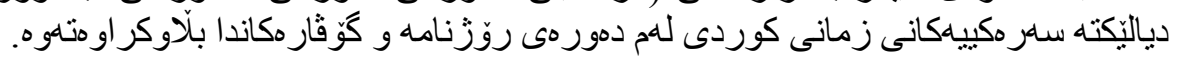

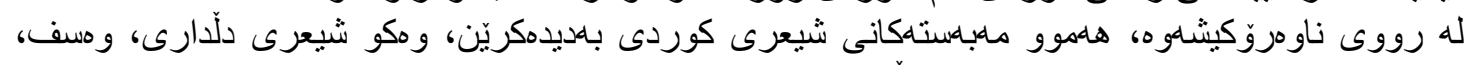

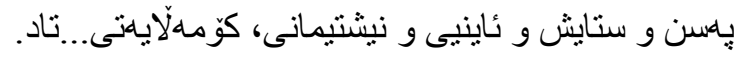

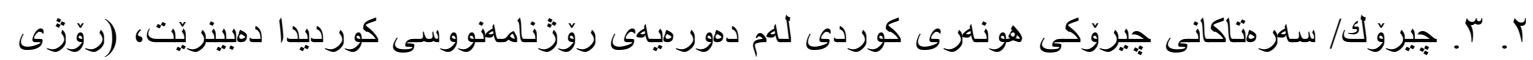

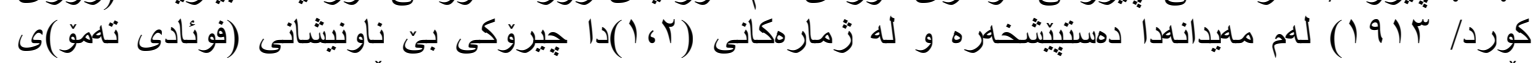

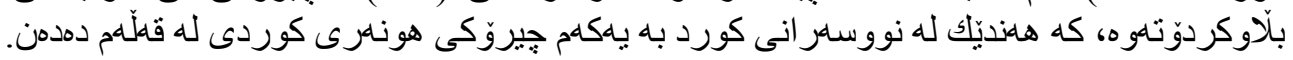

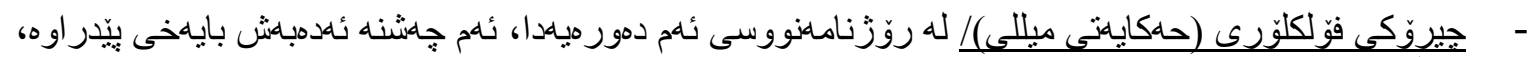

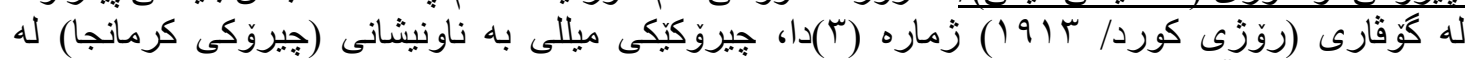

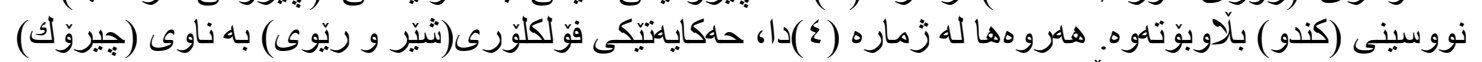

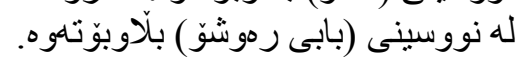

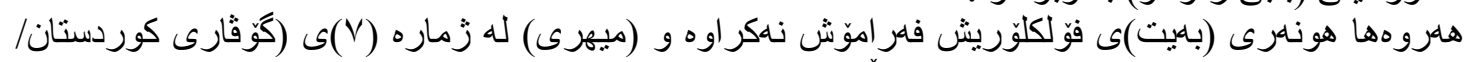

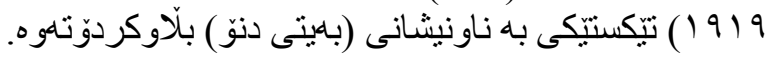

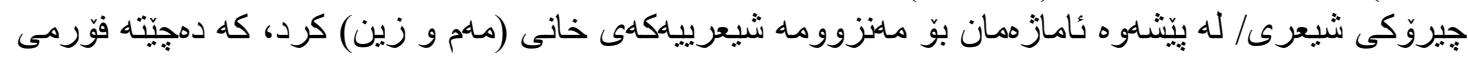

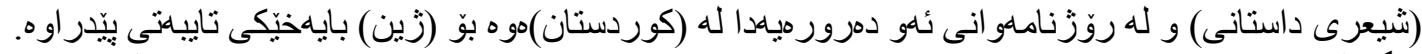

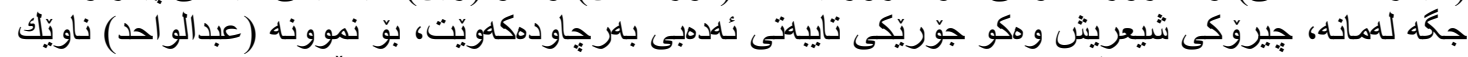

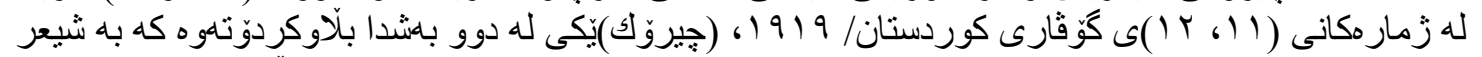

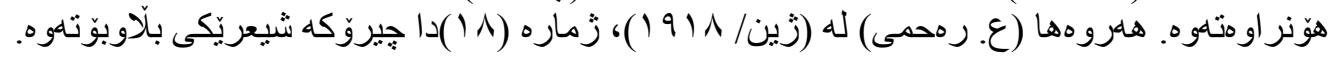

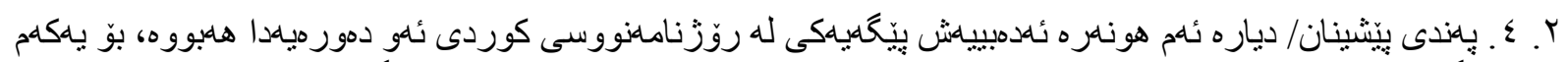

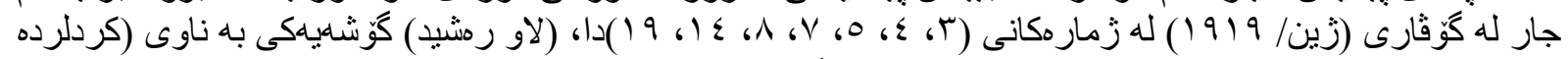

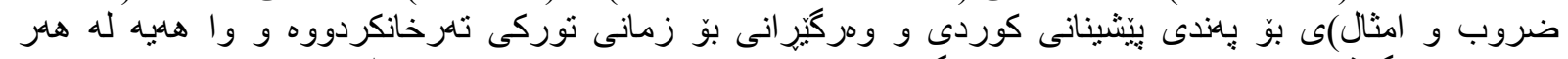

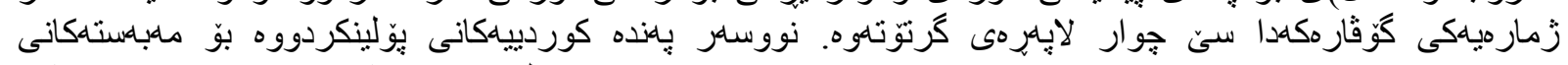

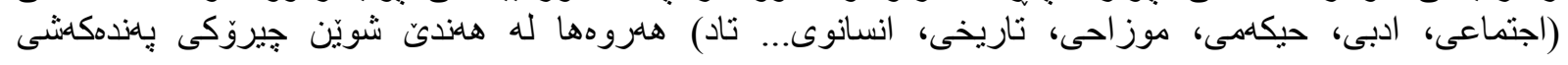

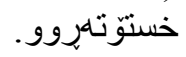

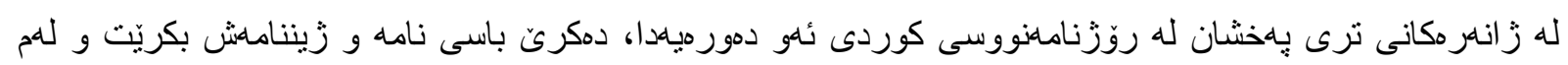

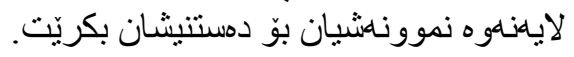




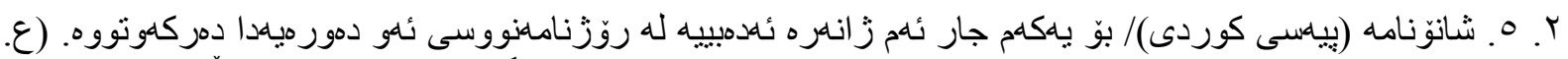

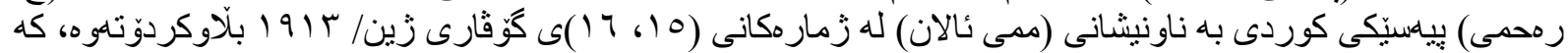

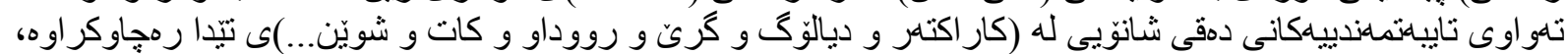

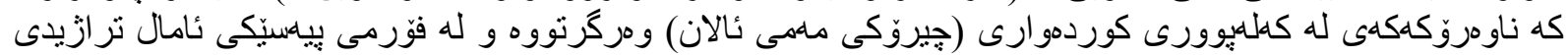
دارشتوتنوه.

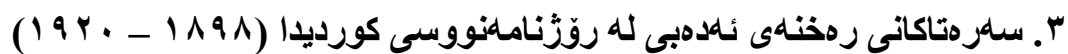

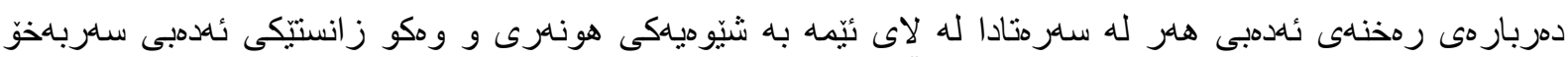

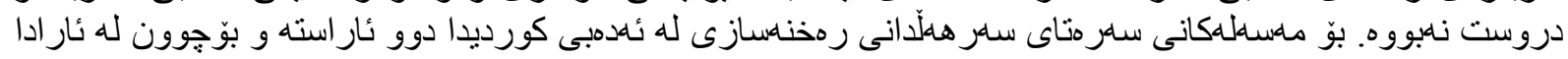

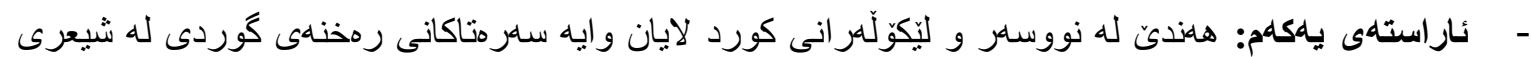

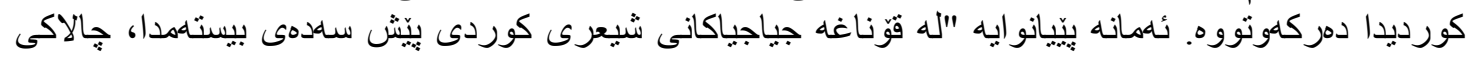

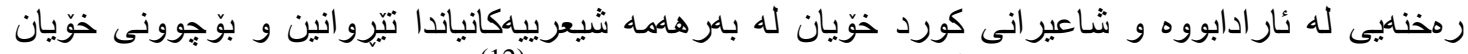

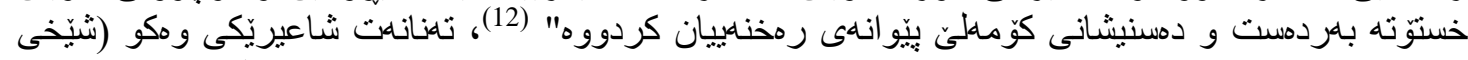

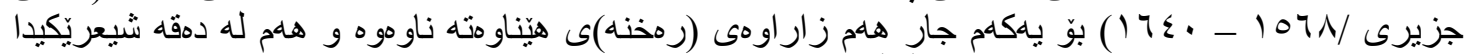

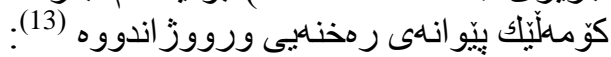

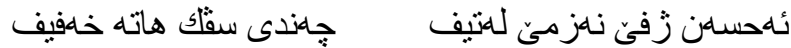

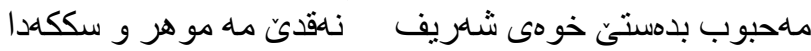

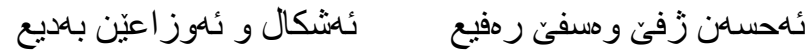

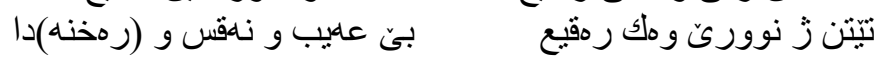

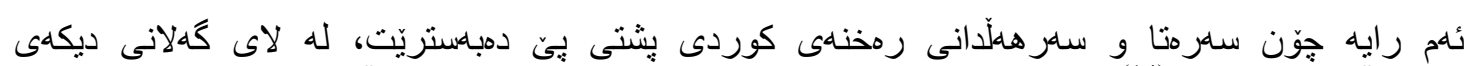

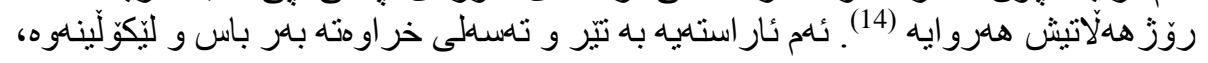

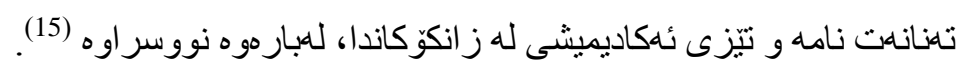

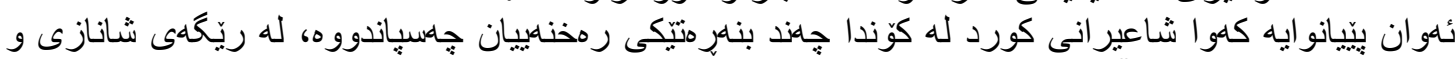

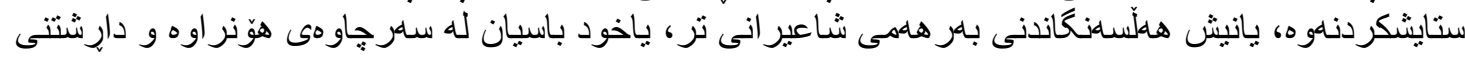

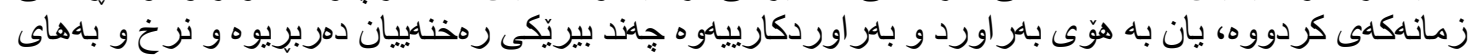

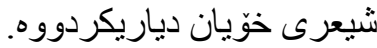

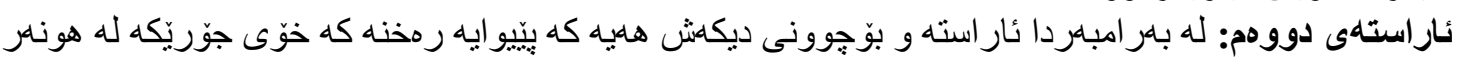

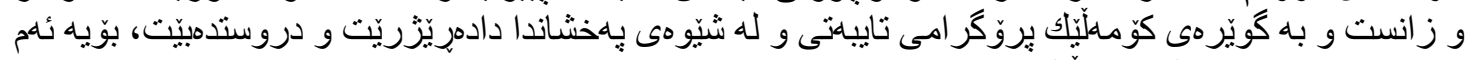

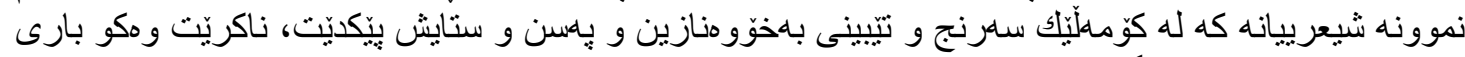

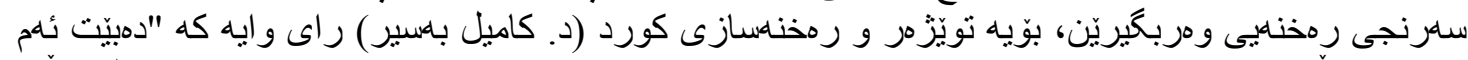

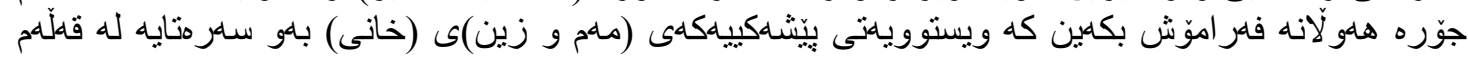

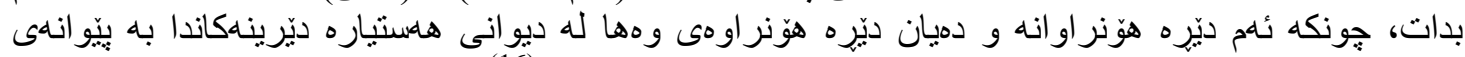

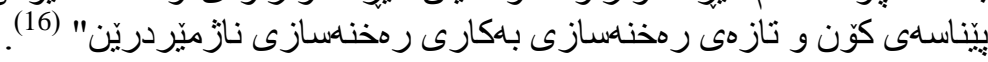

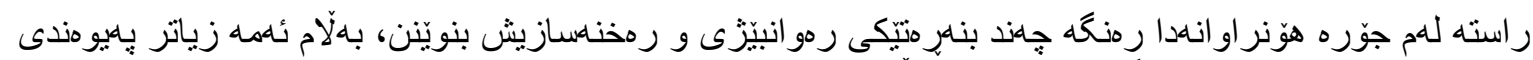

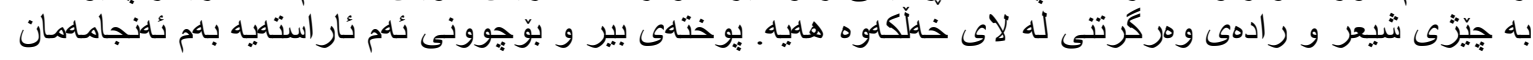

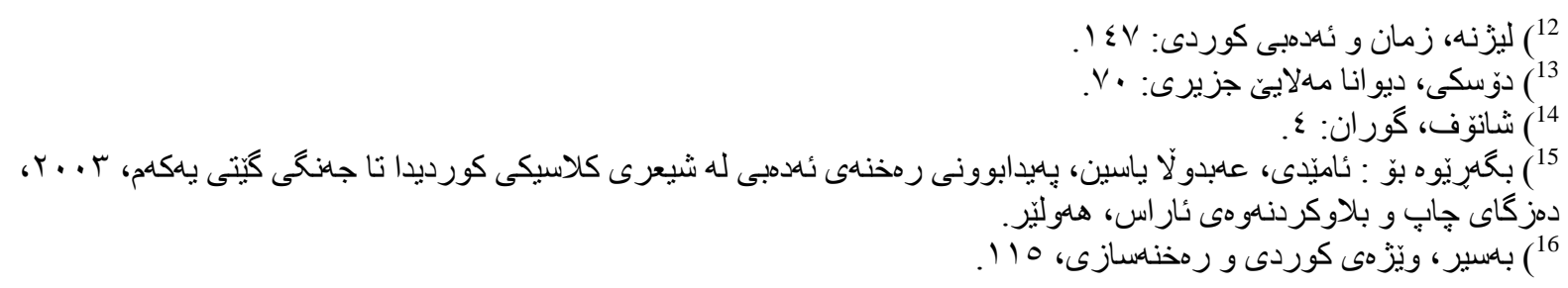




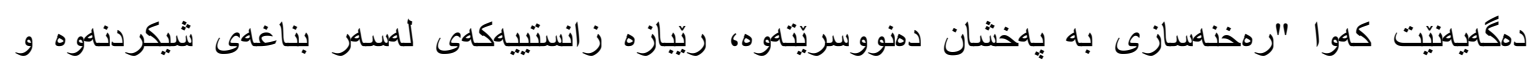

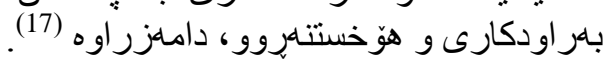

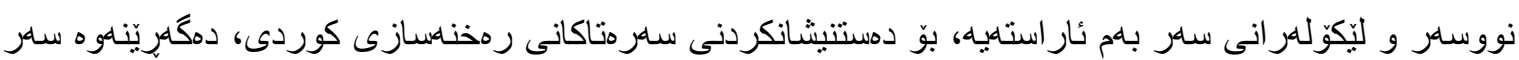

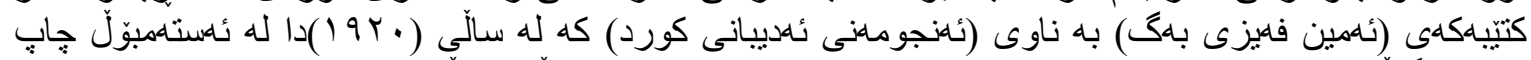

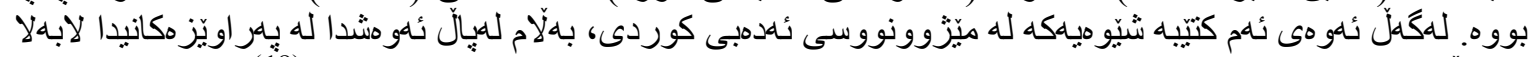

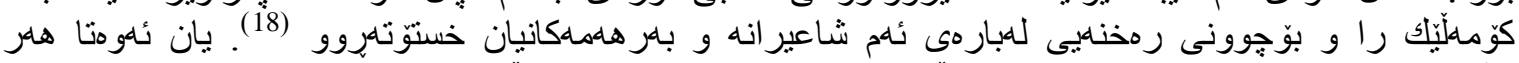

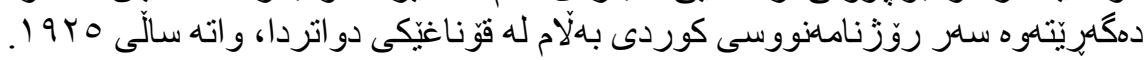

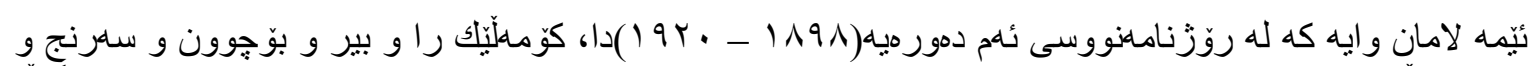

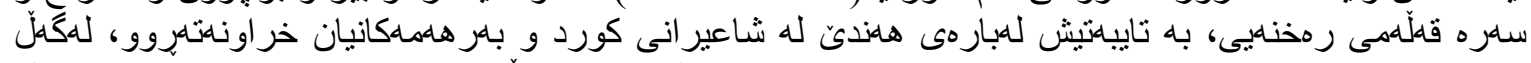

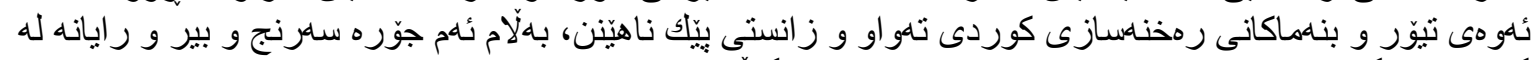

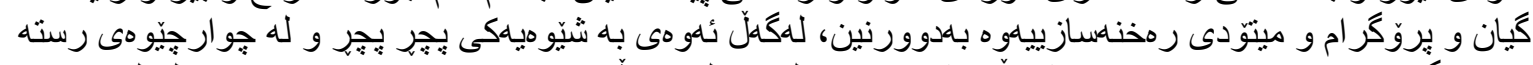

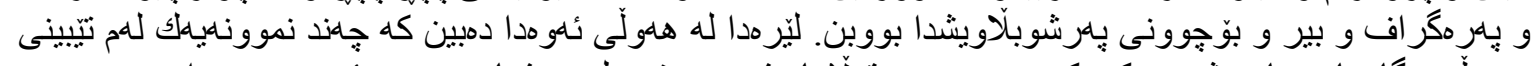

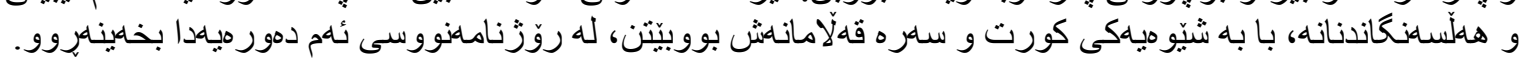

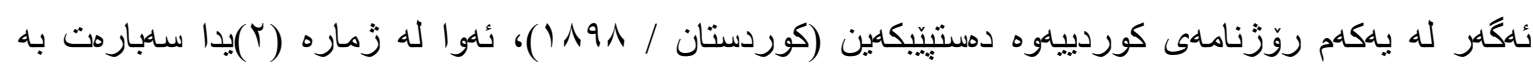

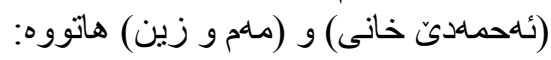

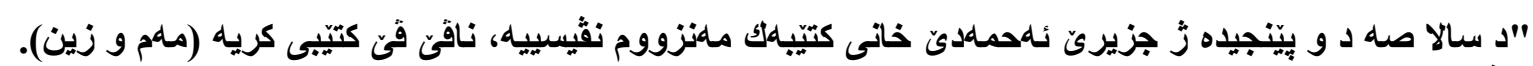

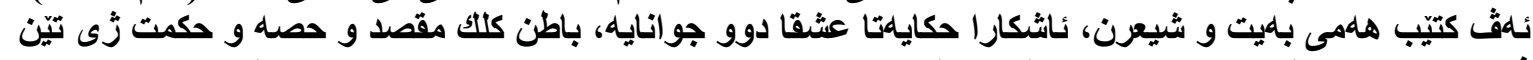

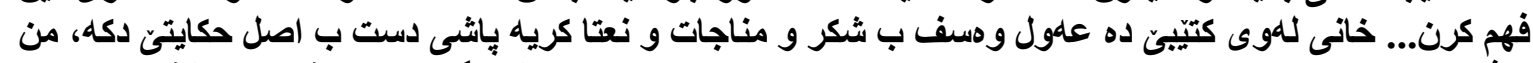

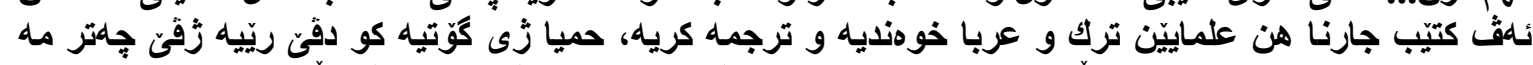

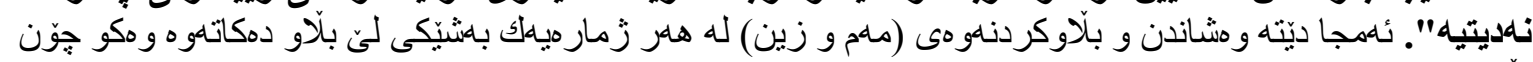

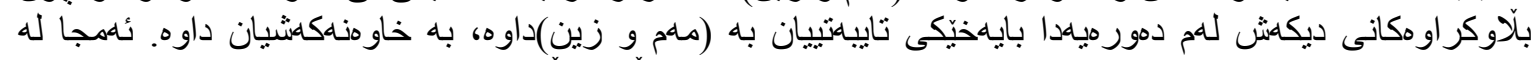

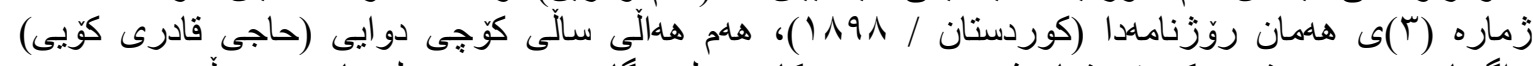

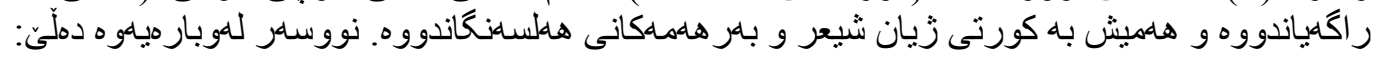

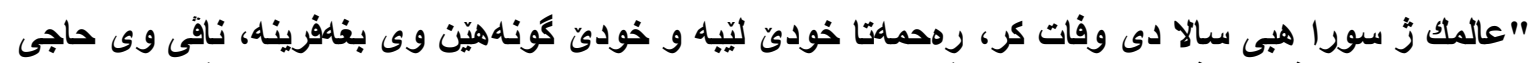

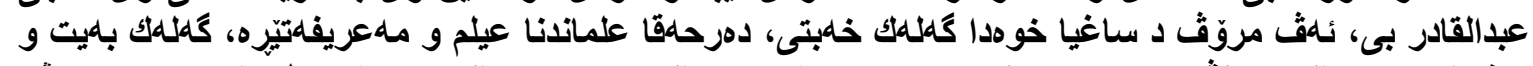

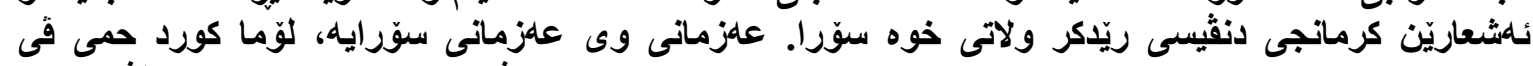

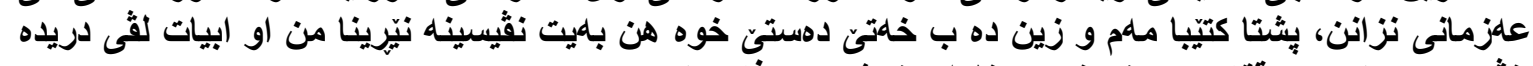

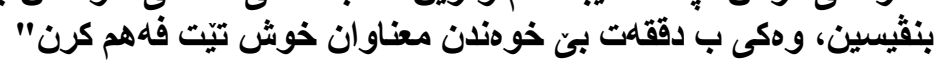

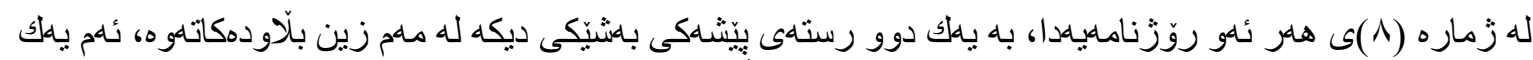

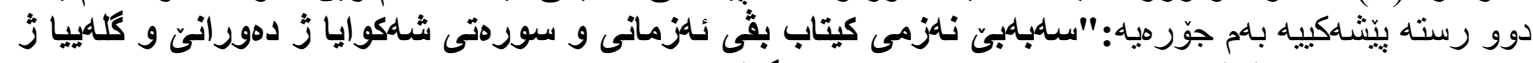

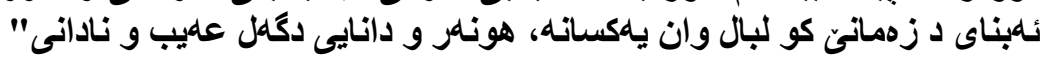

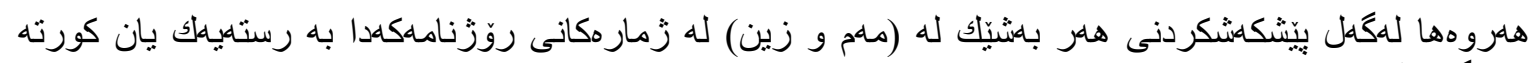

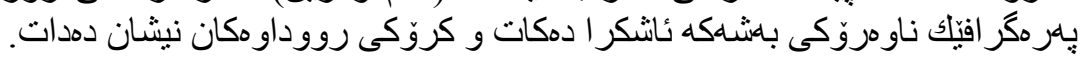

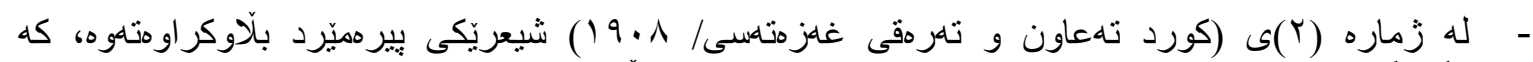

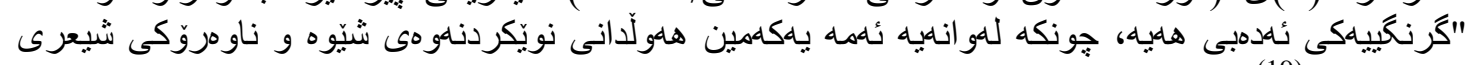

كوردى بكي) (19)

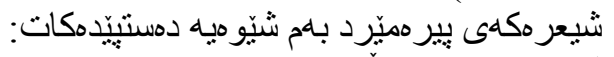

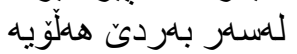

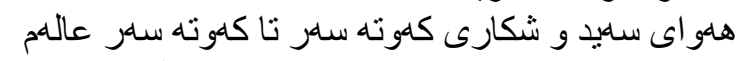

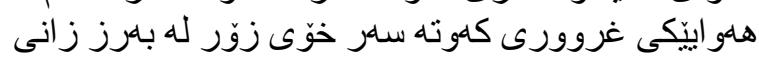

$$
\begin{aligned}
& \text { 18 }
\end{aligned}
$$

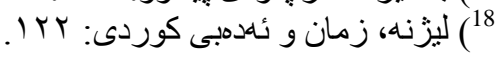

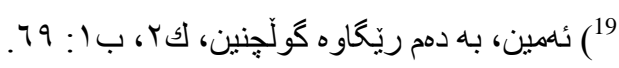




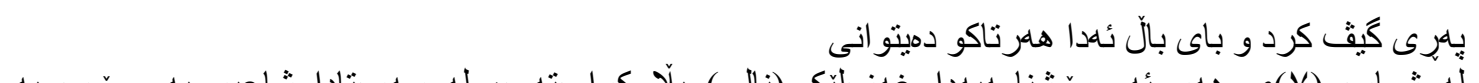

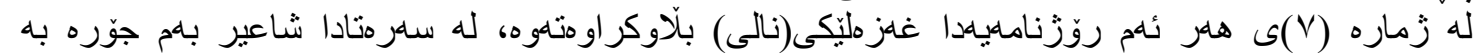

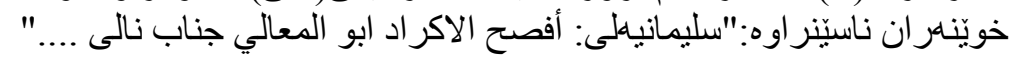

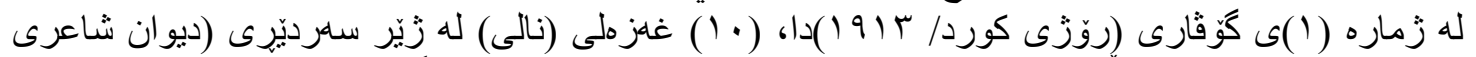

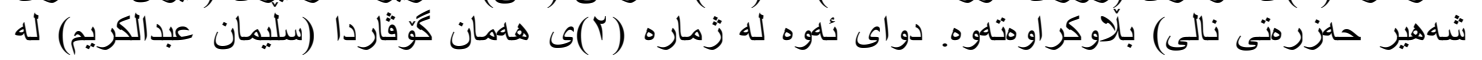

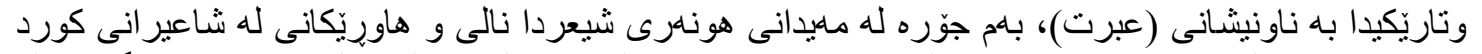

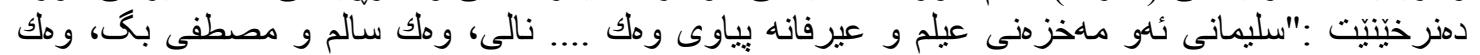

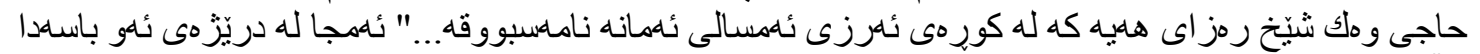

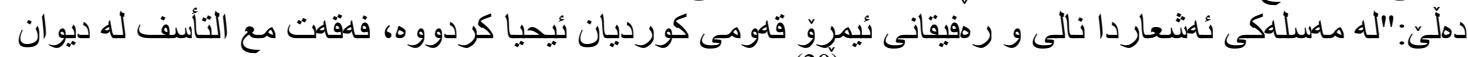

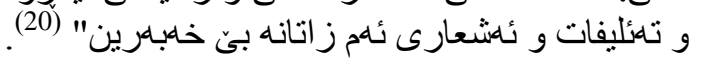

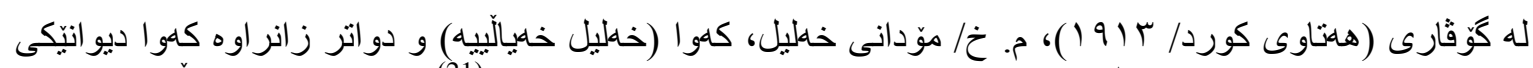

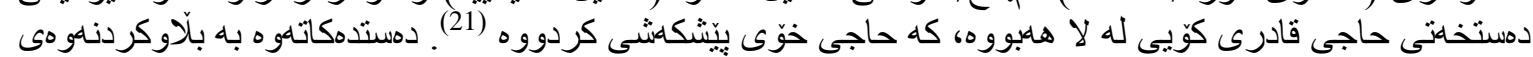

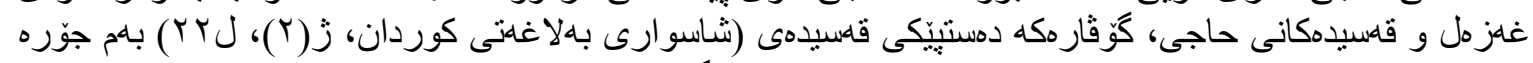

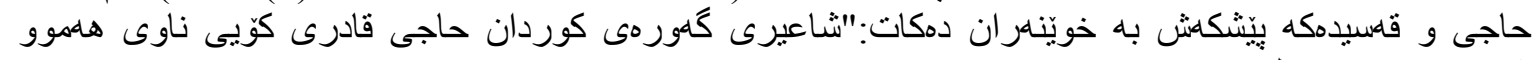

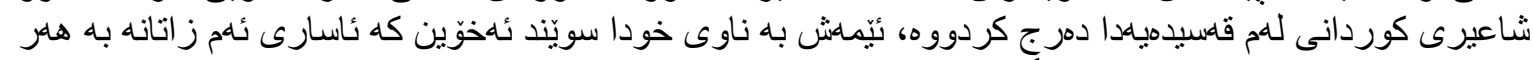

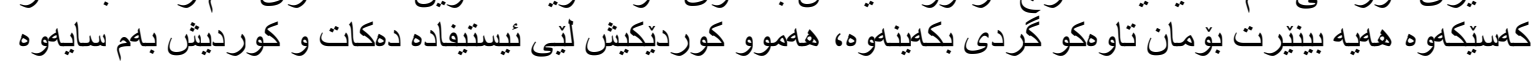

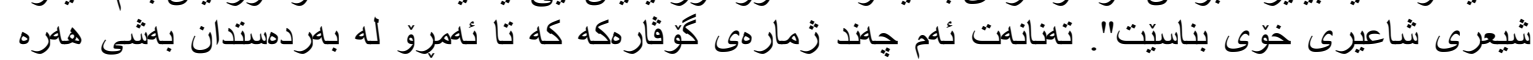

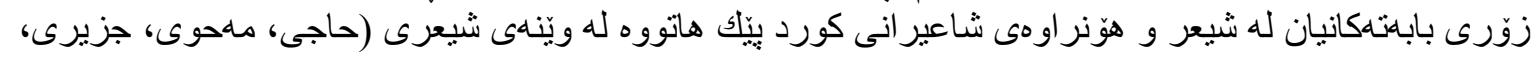

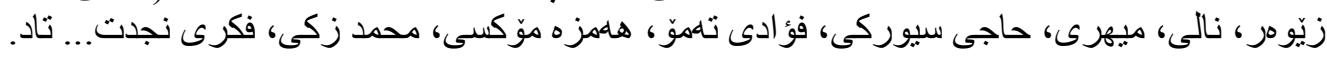

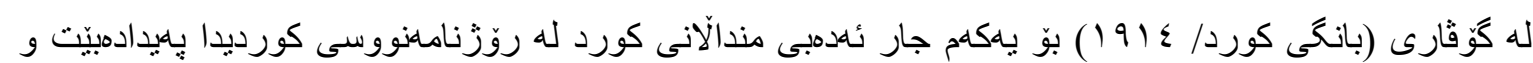

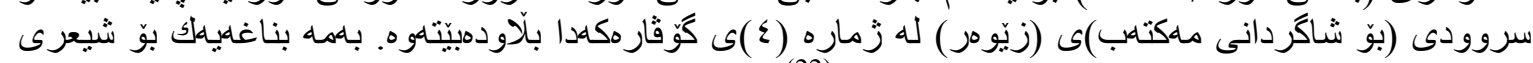

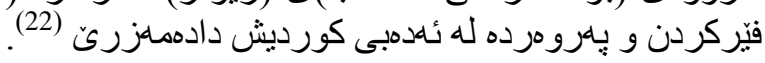

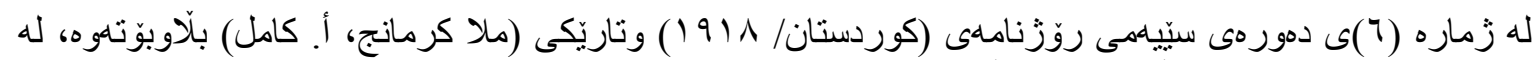

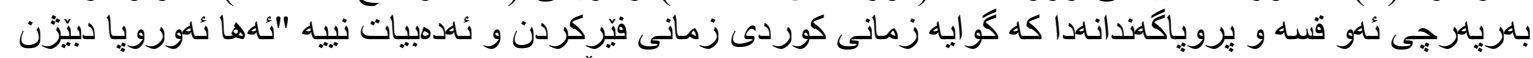

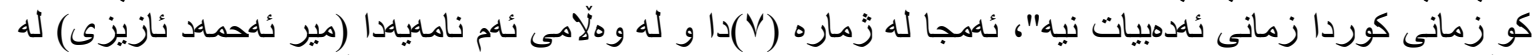

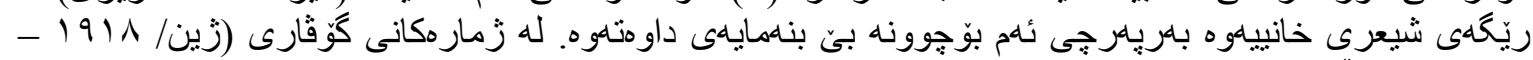

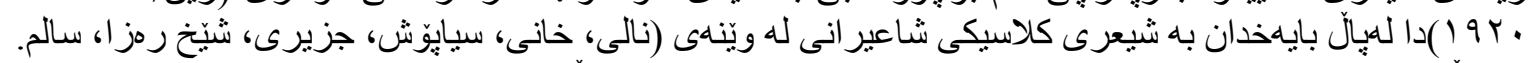

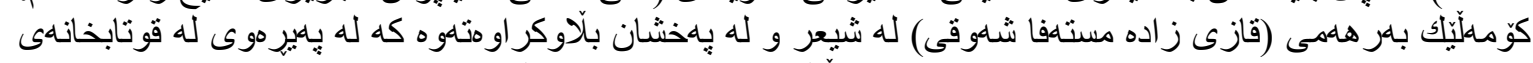

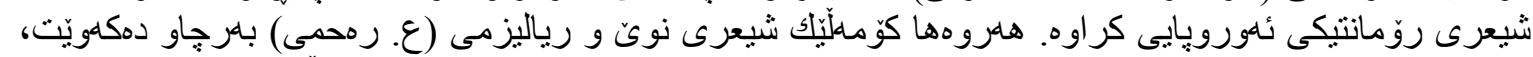

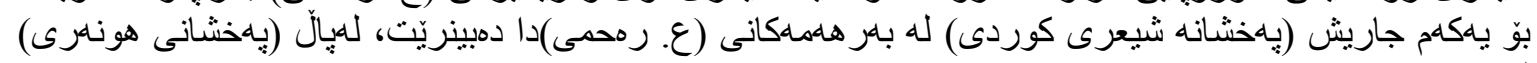

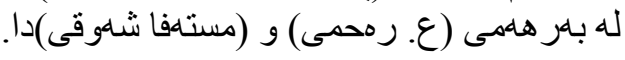

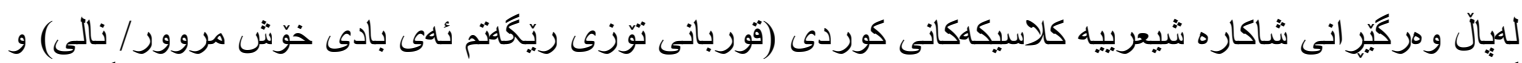

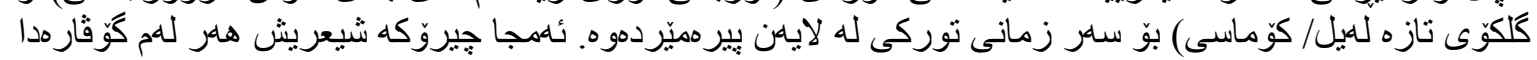

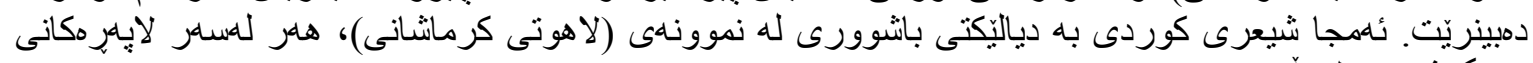

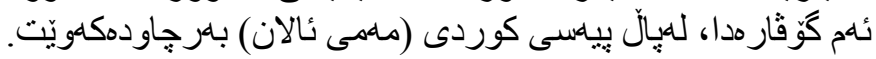

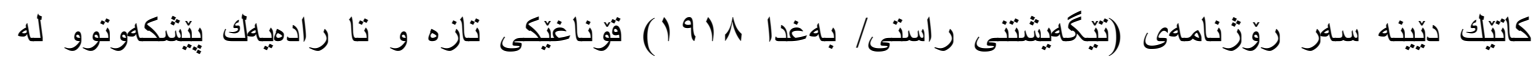

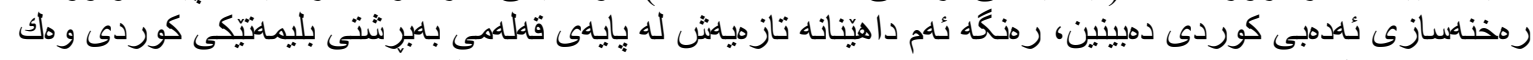

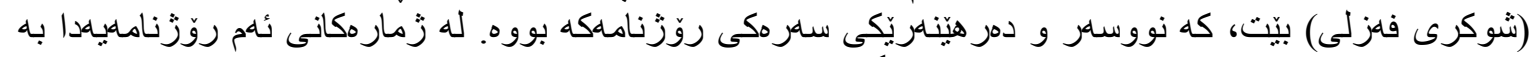

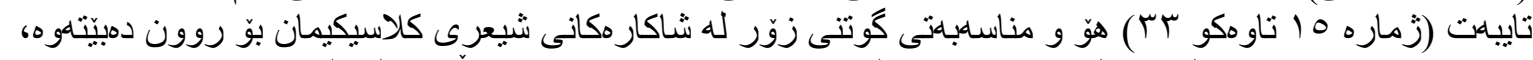

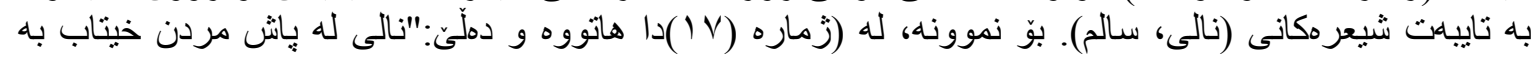

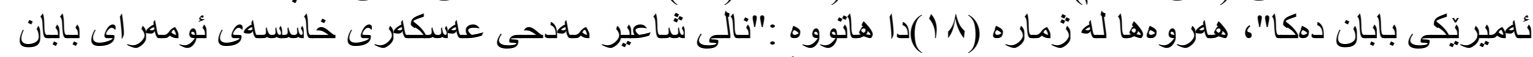

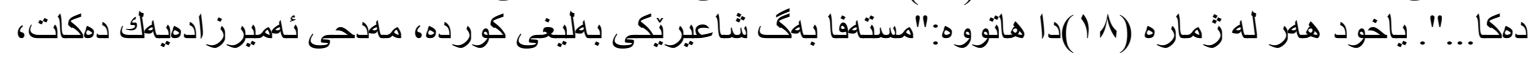

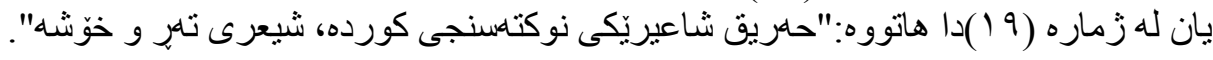

$$
\begin{aligned}
& \text { kroma xabatên kurdolojiê }\left(^{20}\right.
\end{aligned}
$$

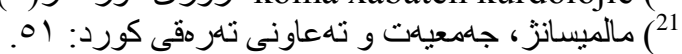

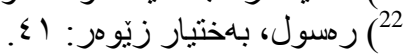




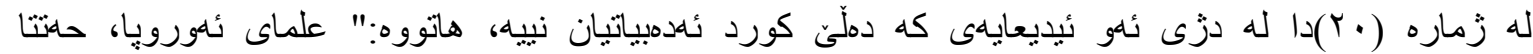

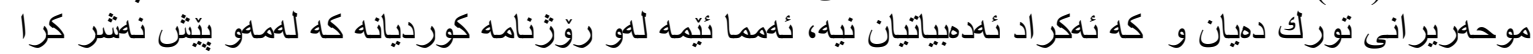

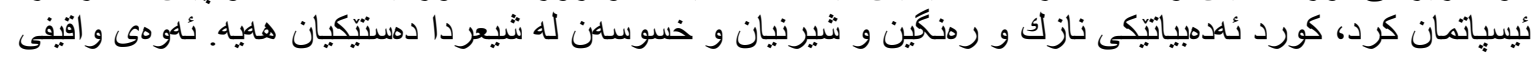

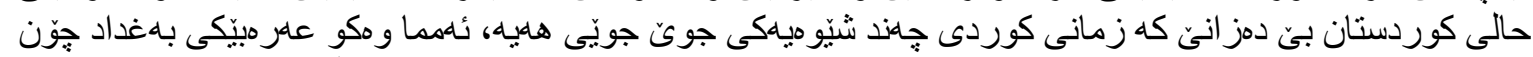

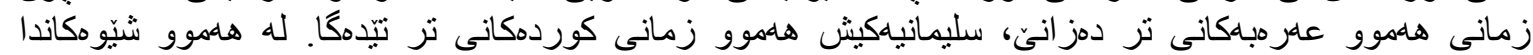

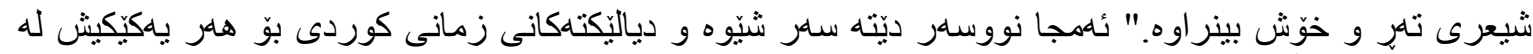

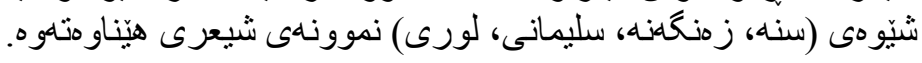

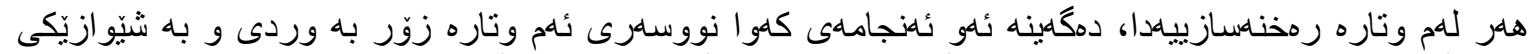

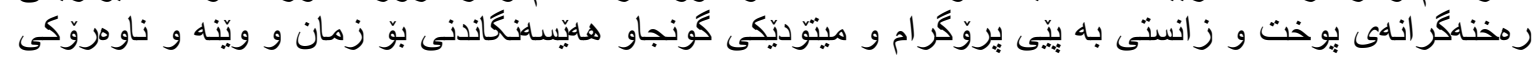
شيعرى كوردى دمكات.

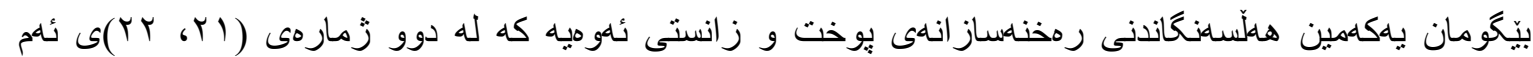

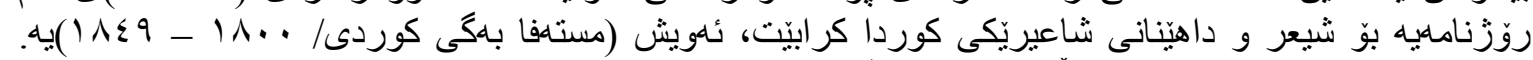

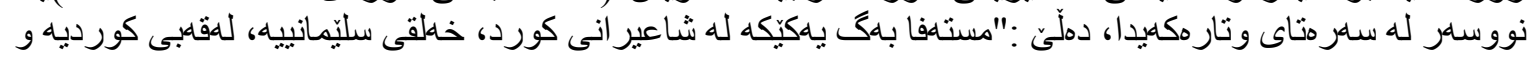

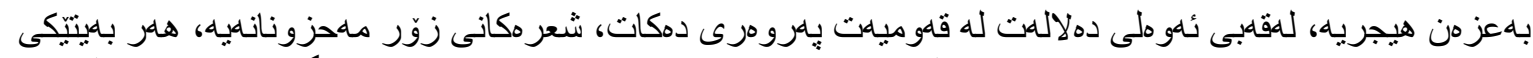

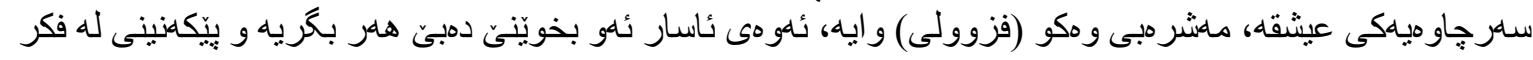

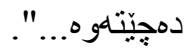

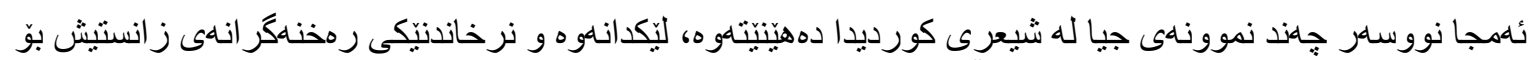

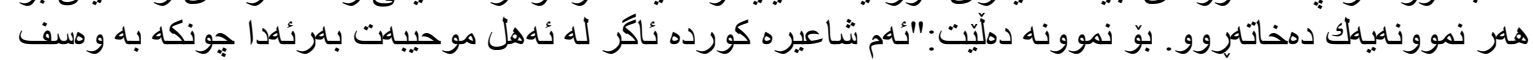

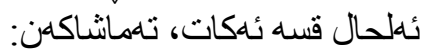

دمروون زامدار و دلّ غهمكينه بيَّ تو

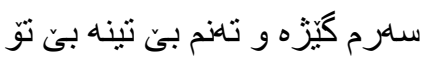

$$
\begin{aligned}
& \text { زمستان معيل ئهكهى يايزه بر اكهم } \\
& \text { بهارى وهستّى من هاوينه بيّ توّ } \\
& \text { ئسوا من بووم به شاى جوملهيى عالهم } \\
& \text { توخوا سا كاكه كيان كهى زينه بيّ تو }
\end{aligned}
$$

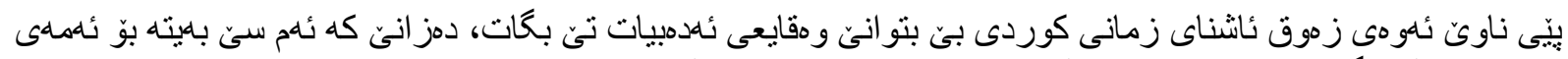

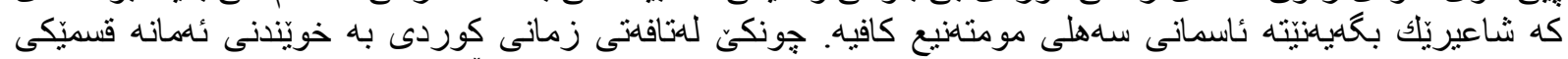

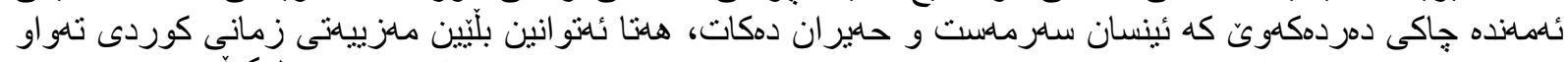

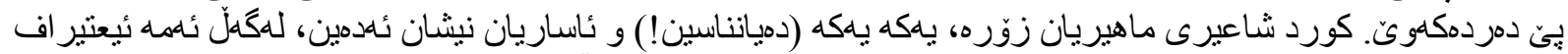

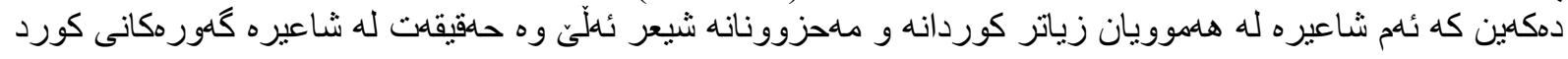
" ملهعدووده....

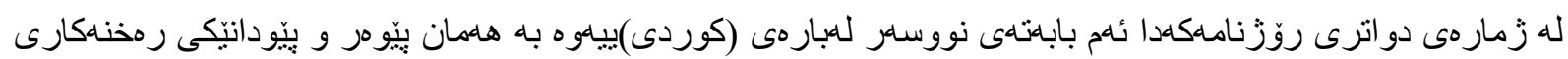

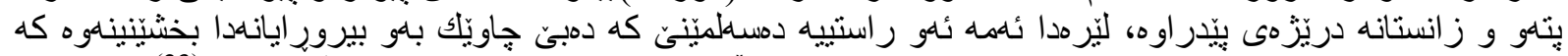

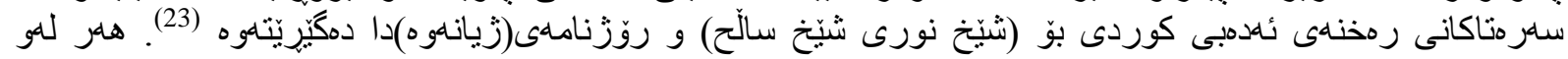

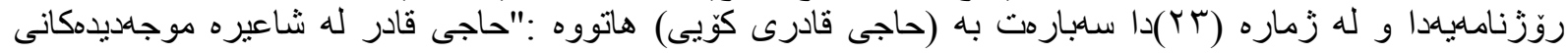

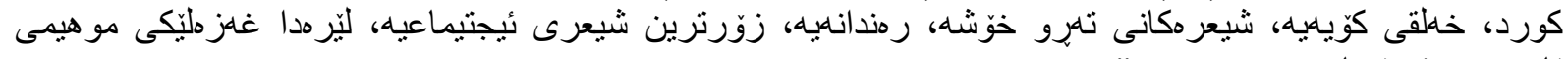

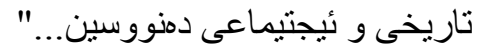

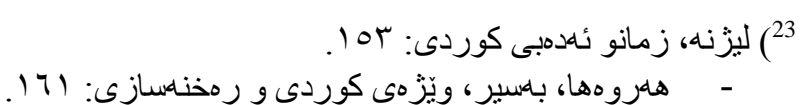




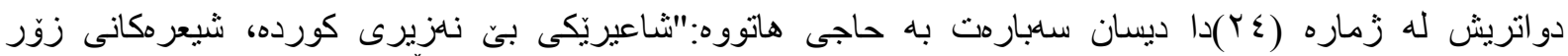

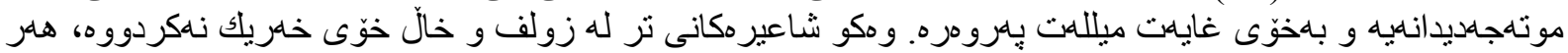

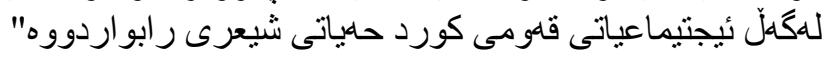

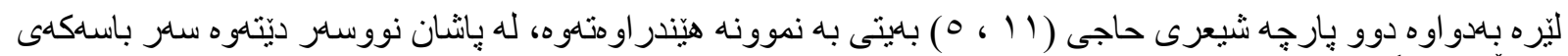

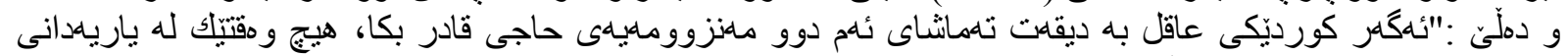

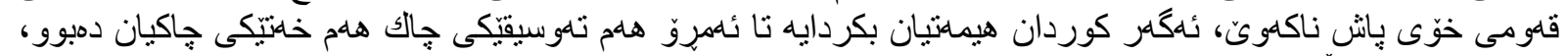

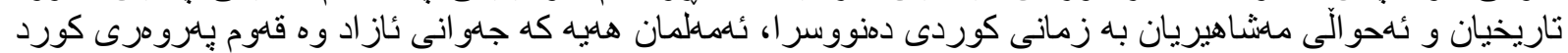

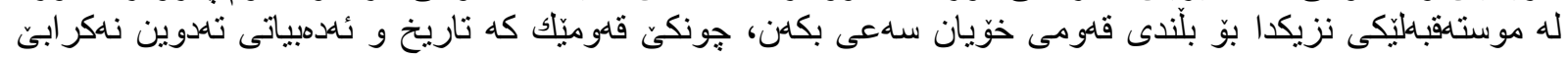

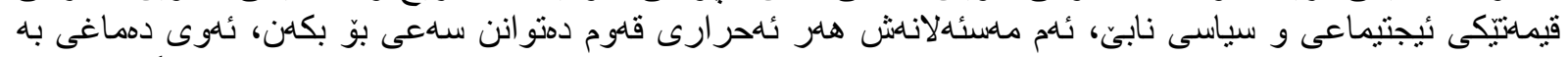

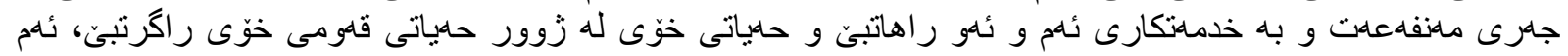

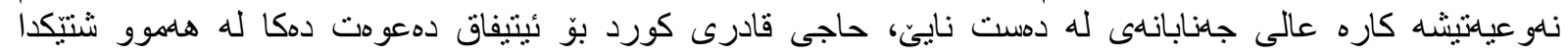

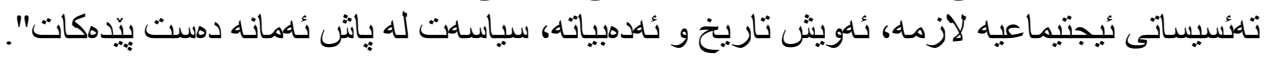

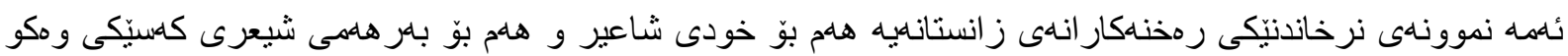

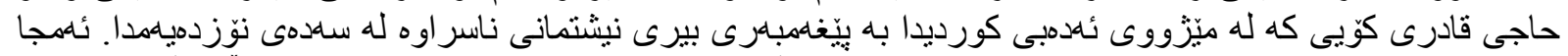

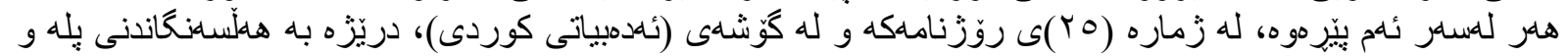

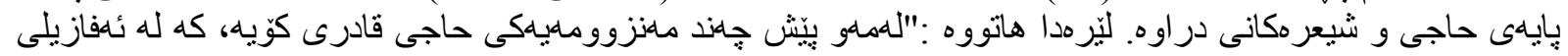

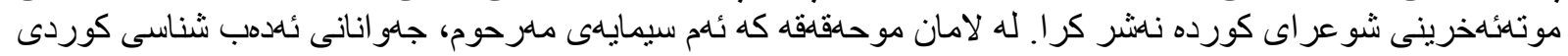

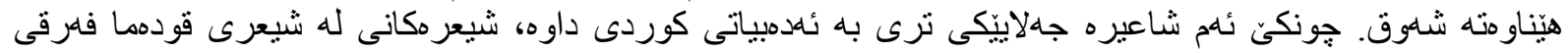

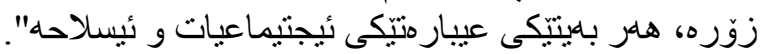

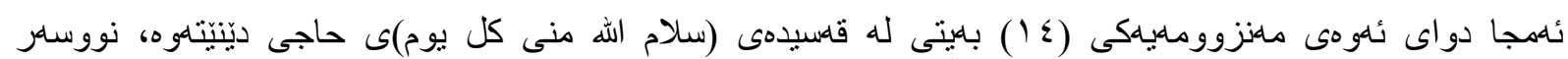

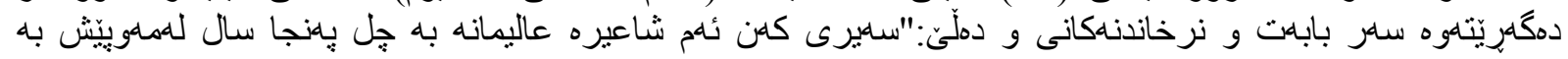

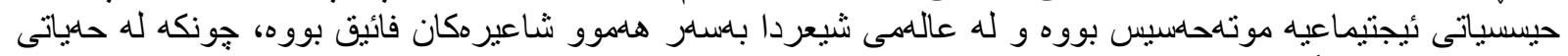

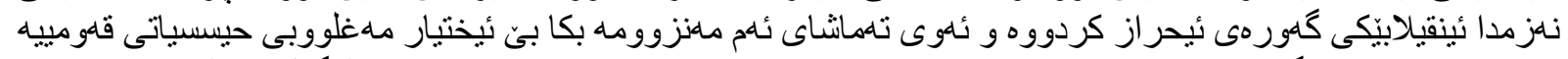

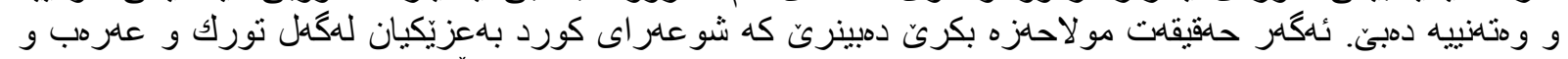

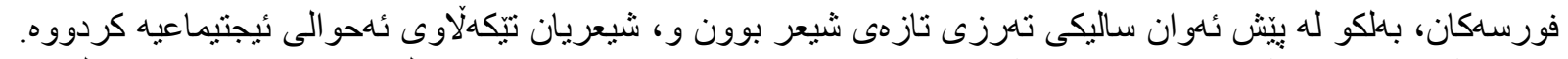

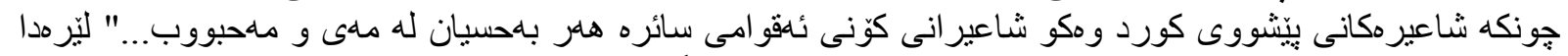

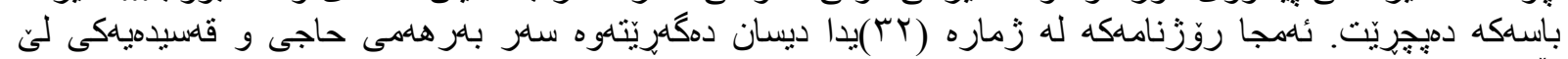

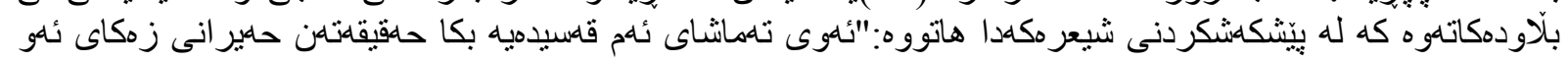

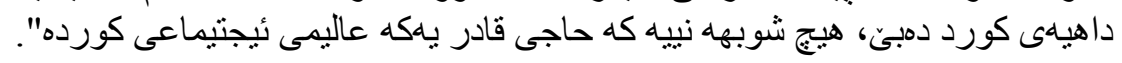

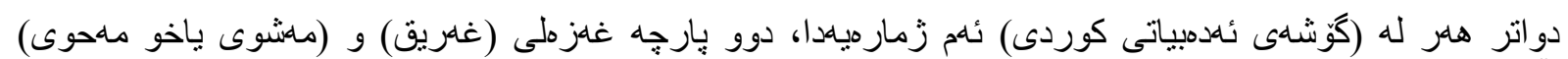

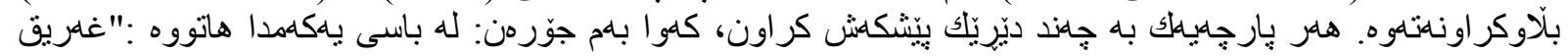

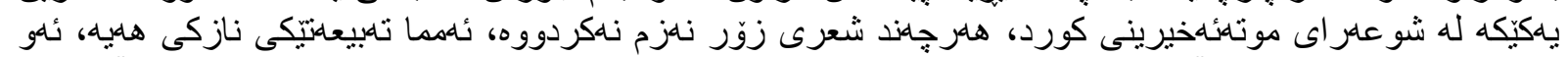

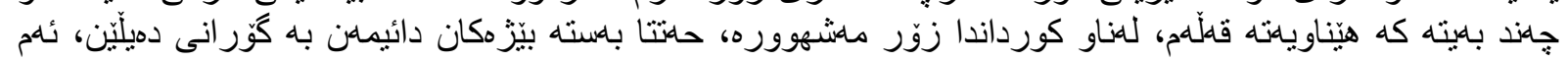

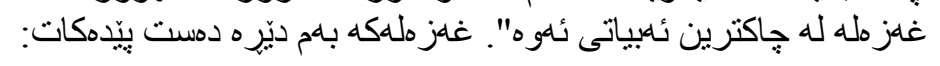

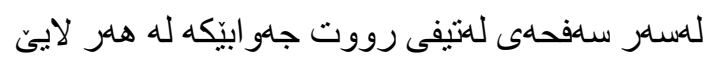

شكستهى خهنتى دوو ئمبروّت، خممى زولفى جليبياييّ

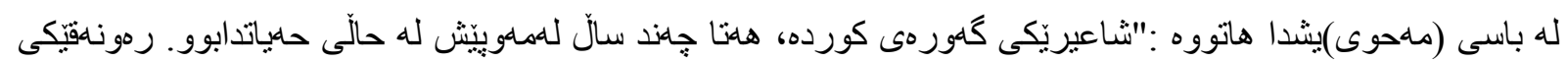

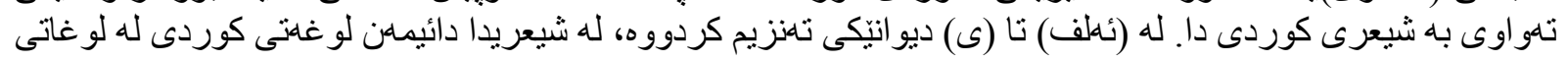

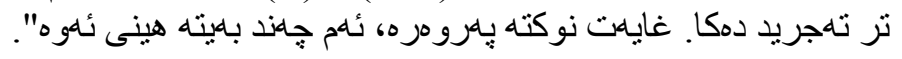

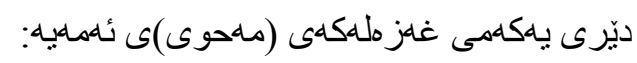

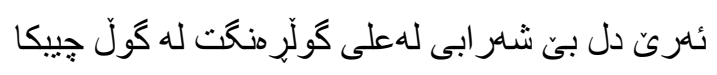

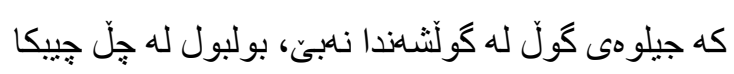




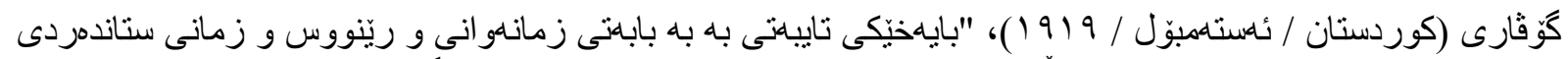

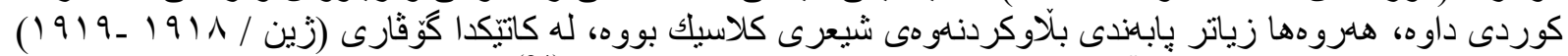

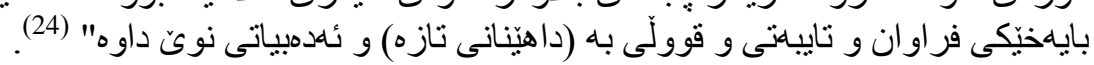

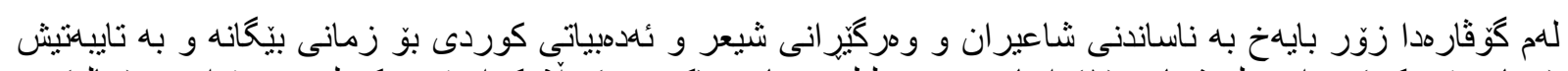

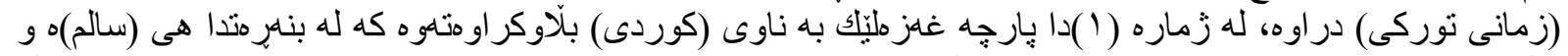

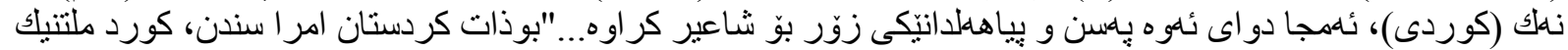

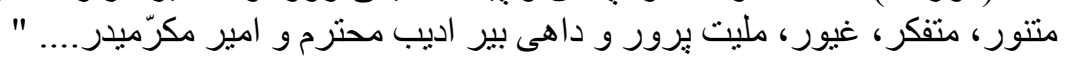

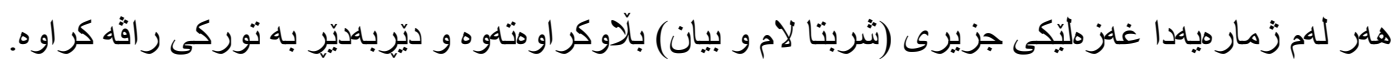

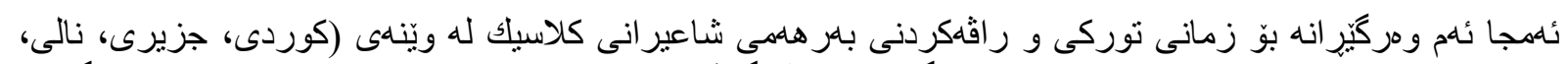

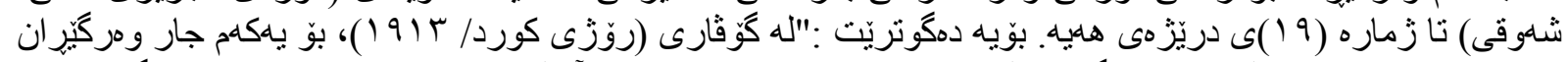

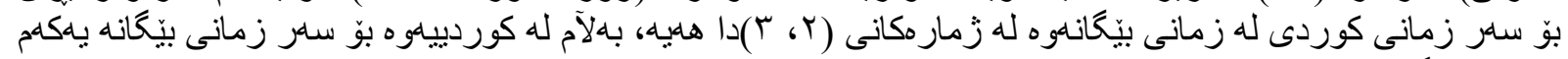

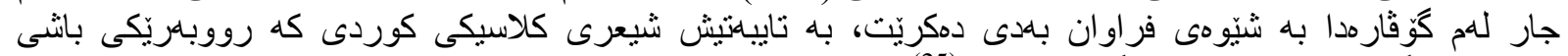

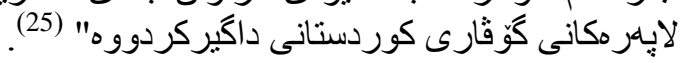

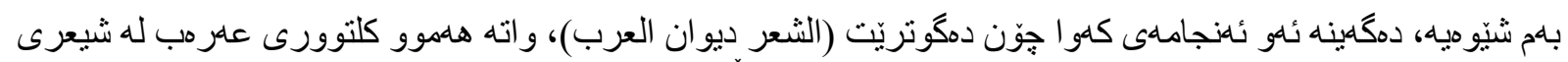

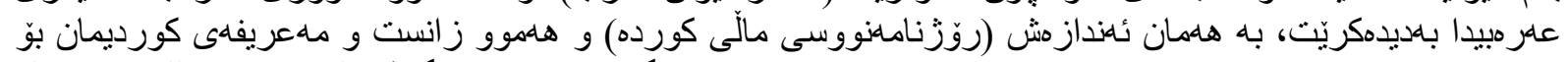

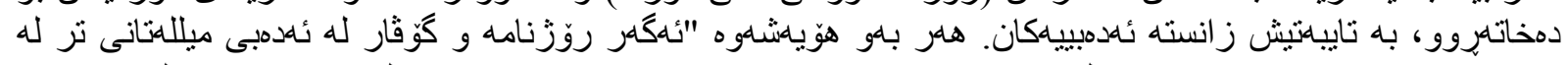

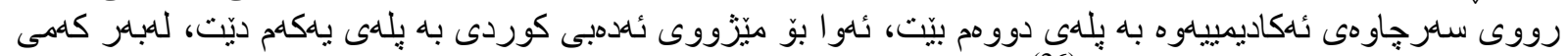

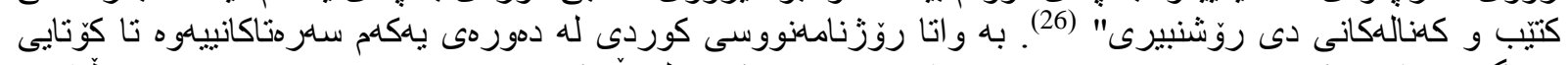

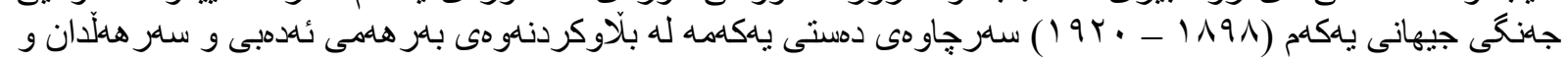

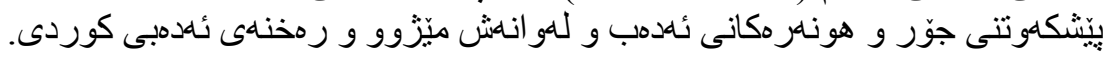




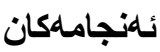

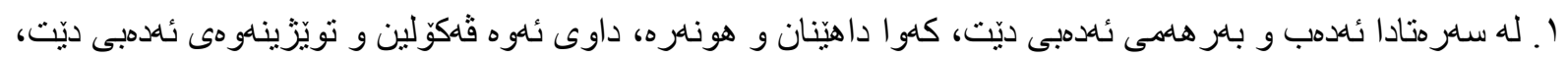

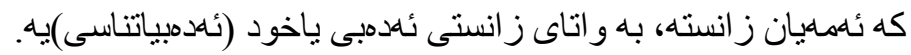

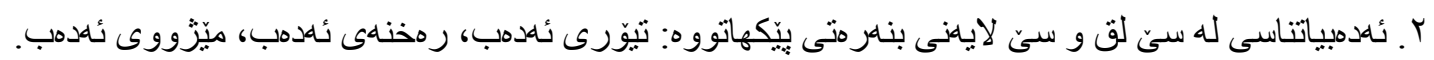

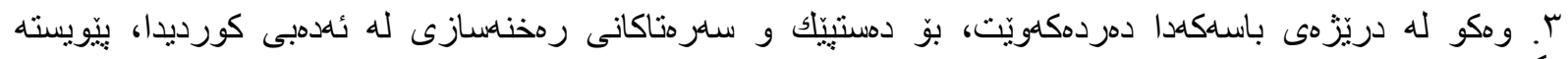

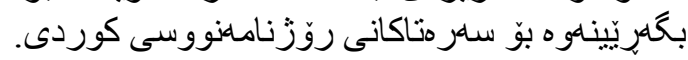

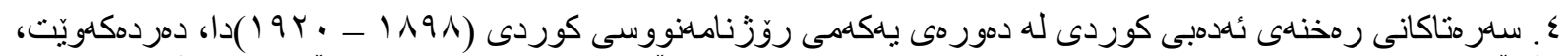

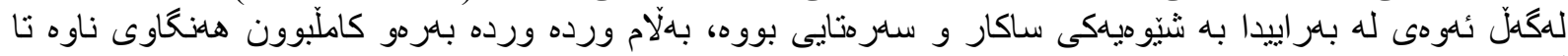

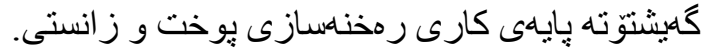

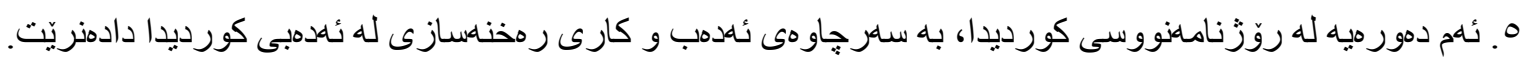

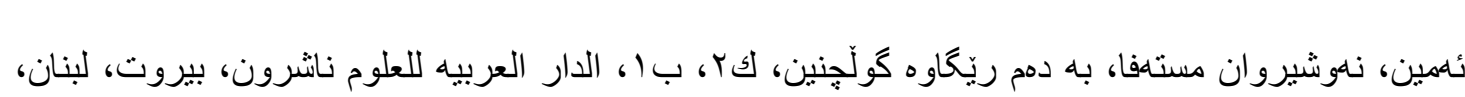

$r+14$

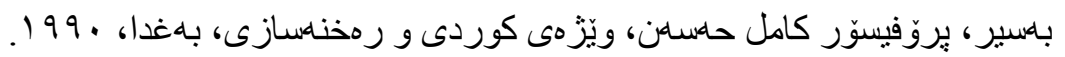

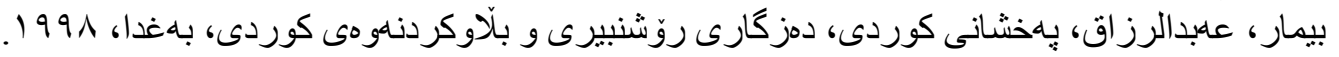

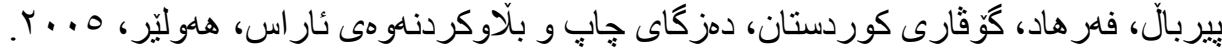

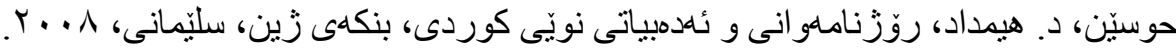

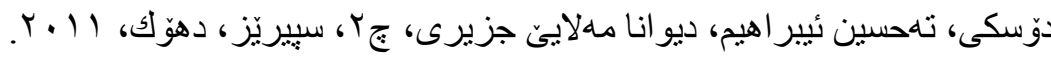

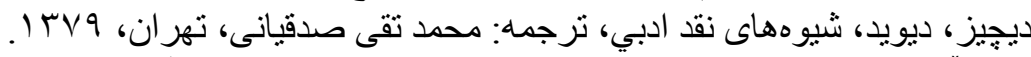

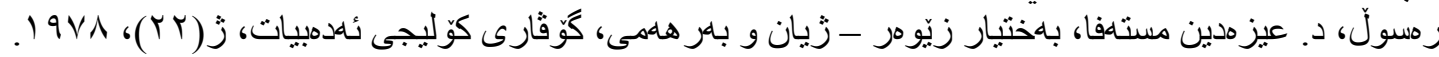

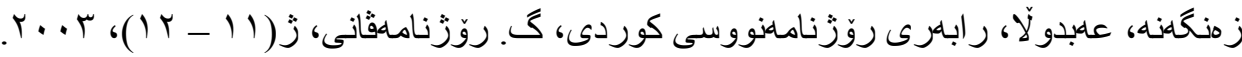

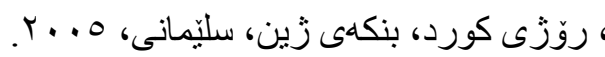

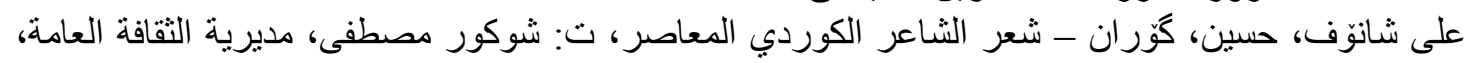

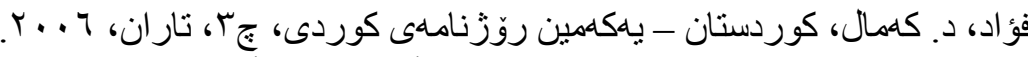

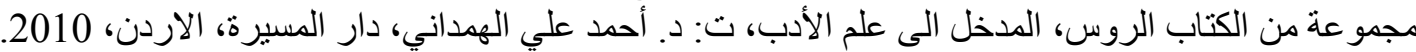

KOMA XABATÊN KURDOLOJIYÊ , ROJÎ KURD - 1913 ，WEŞANÊN

ENISTITTUYA KURDÎ YA STENBOLÊ, 2013.

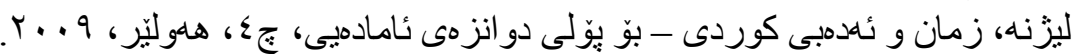

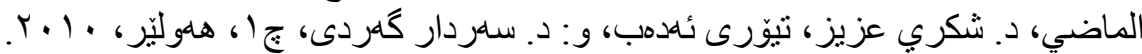

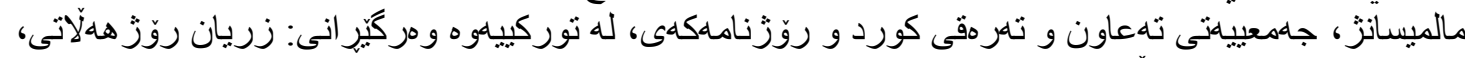

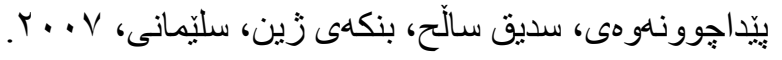

